\title{
Benzoannelated Centropolyquinanes. Part 21. Centrohexaindane: Three Complementary Syntheses of the Highest Member of the Centropolyindane Family
}

\author{
Dietmar Kuck, ${ }^{*}$ Andreas Schuster, Bernd Paisdor and Detlef Gestmann \\ Fakultät für Chemie, Universität Bielefeld, Universitätsstraße 25, D-33615 Bielefeld, Germany
}

\begin{abstract}
The syntheses of centrohexaindane 1 , a unique hydrocarbon bearing six mutually fused indane units in a centrohexacyclic, $T_{\mathrm{d}}$ symmetrical, and topologically nonplanar framework is reported in full detail. Three independent and complementary synthetic routes have been developed making use of derivatives of the readily accessible centrotriindanes 9,10 and $11\left(R=\mathrm{CH}_{3}\right)$ and centrotetraindane 13 (fenestrindane). The most efficient synthesis gives the title compound $\mathbf{1}$ in seven steps starting from indane-1,3-dione 15 in $40 \%$ yield, involving the 'broken' fenestrane 10 ('broken-fenestrane route'). Also starting from dione 15. an even shorter route furnishes our target molecule 1 in six steps via triptindanetrione 24 in $25 \%$ yield ('propellane route'). Both of these routes surpass our first synthesis reported in 1988 via fenestrindane 13 which comprises eleven steps and gives a 7.5\% overall yield from indanedione 15 ('fenestrane route'). The three routes allow the six benzene rings of compound 1 to be introduced in complementary ways, thus promising the synthesis of centrohexaindane derivatives with various substitution patterns. Particularly remarkable key steps of the syntheses of compound $\mathbf{1}$ are, inter alia: (i) single and two-fold condensation of benzene by $\mathrm{AlBr}_{3}$-catalysed Friedel-Crafts reaction of cyclic 1,3-dibromides, (ii) unusual three-fold addition of phenyllithium to a 1,3,3'-triketone (compound 24), (iii) two-fold and even three-fold cyclodehydration. Finally, a low-yield formation of compound 1, among other products, has been observed upon cyclodehydrogenation of 10-methyl-1,4,7-triphenyltribenzotriquinacene 32 , which is obtained in two steps from 10 -methyltribenzotriquinacene $11(\mathrm{R}=\mathrm{Me})$, with $\mathrm{Pd} / \mathrm{C}$ at $500^{\circ} \mathrm{C}$. The spectroscopic properties of compound 1 are presented along with some unique structural features of its rigid centrohexacyclic framework.
\end{abstract}

Centrohexacyclic compounds ('centrohexacyclanes', ${ }^{2}$ a) comprise molecular species bearing six mutually fused rings, all of them sharing a central carbon or hetero atom. The members of this unusual class of polycyclic compounds are characterized by some remarkable and rare structural features: the central tetracoordinated atom $(\mathrm{Z})$ is bonded to four other tetracoordinated atoms $(A)$, and this central unit, $Z\left(A_{4}\right)$, is bridged by six atomic groups or atoms $(B)$ connecting the four outer atoms in a pairwise manner, according to the six edges of a tetrahedron (b), to give a highly condensed polycyclic $\mathrm{Z}\left(\mathrm{A}_{4}\right)\left(\mathrm{B}_{6}\right)$ arrangement of formal $T_{\mathrm{d}}$ symmetry. The connectivity of centrohexacyclic species (c) corresponds to the graph $K_{5}$, a complete graph containing five mutually connected vertices. ${ }^{3} \mathrm{As}$ a particular feature, $K_{5}$ graphs are topologically nonplanar; that is, any two of their edges (lines connecting a pair of vertices) must intersect when the graph is projected onto a plane, as illustrated in (d), for example ${ }^{3-6}$ (see Fig. 1).

In organic chemistry, topologically nonplanar molecules are extremely rare. In 1981, Simmons III and Maggio ${ }^{7-9}$ and Paquette and Vazeux ${ }^{10}$ published the synthesis of the first organic $K_{5}$ compound, the 'Simmons-Paquette molecule' $2 ;{ }^{4}$ a little later, Walba reported on the synthesis of a Möbius striptype polycycle, ${ }^{11}$ yet another heterocyclic structure containing several ether groups, which corresponds to the likewise topologically nonplanar (bipartite) graph $K_{3,3} \cdot{ }^{3-6}$ In contrast, the related parent hydrocarbons, centrohexaquinane $\mathbf{3}$, and its congener, centrohexaquinacene 4 , have remained elusive, as reported by Simmons III and co-workers ${ }^{9}$ and later in an extended work by Paquette et al. ${ }^{12}$. However, hexacycles 3 and 4 have been studied by semiempirical calculations, ${ }^{2,13,14}$ and partially benzoannelated centrohexaquinanes $\dagger$ and a derivative of compound $4^{17}$ have been synthesized recently.

† The pentabenzo and a 'propella-tribenzo' derivative of compound 3 have been synthesized recently. ${ }^{15,16}$

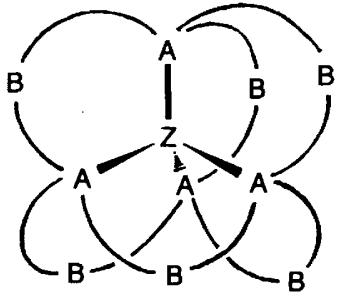

a

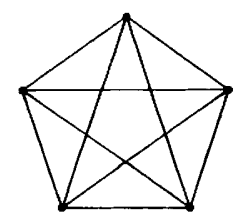

c

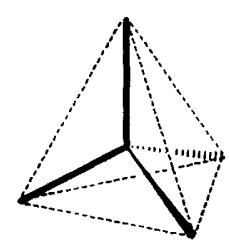

b

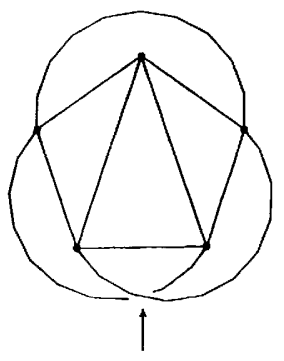

d
Fig. 1

The first topologically nonplanar hydrocarbon was the title compound, centrohexaindane 1 , synthesized in our laboratory for the first time in $1988 .{ }^{18}$ This centrohexacycle bears a neopentane core $(\mathrm{Z}=\mathrm{A}=$ carbon) bridged by six $o$-phenylene units $\left(\mathrm{B}=o-\mathrm{C}_{6} \mathrm{H}_{4}\right.$ in a). This achievement has been the basis for our extensive synthetic research on both novel homocyclic ${ }^{15-17}$ and novel heterocyclic centrohexacyclanes such as compounds 5-8, which have been described 


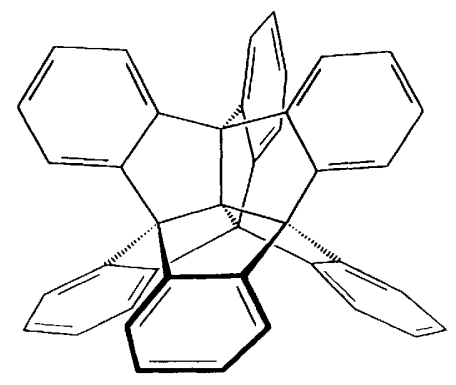

$1 \quad\left(T_{\mathrm{d}}\right)$

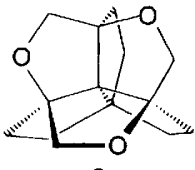

2

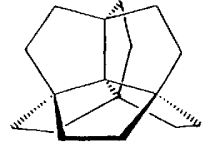

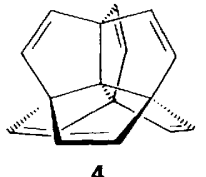

recently. ${ }^{15,19,20}$ In the course of that work, two alternative syntheses of compound 1 were developed and have been communicated briefly. ${ }^{16,20}$
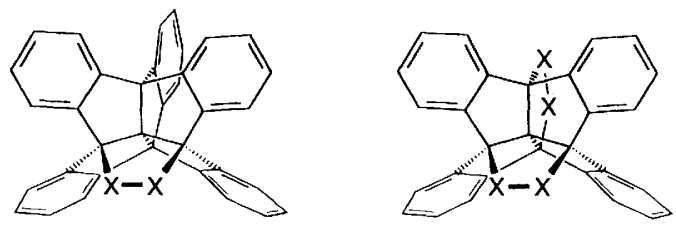

5

$$
\begin{aligned}
& (X=0) \\
& (X=S)
\end{aligned}
$$$$
6
$$$$
7
$$$$
8
$$

Inorganic and organoelement compounds with centrohexacyclic structures have been known since 1934 when Pauling and Sherman ${ }^{21}$ suggested the $Z\left(A_{4}\right)\left(B_{6}\right)$ arrangement for basic beryllium acetate $\mathrm{O}\left(\mathrm{Be}_{4}\right)(\mathrm{OAc})_{6}$ containing six six-membered rings fused at the central $\mathrm{O}\left(\mathrm{Be}_{4}\right)$ unit. Later, Tulinsky and Worthington ${ }^{22}$ determined the detailed structure of this 'centropolysexane' 2 analogue, and, in the following years, related neutral species like dialkyl phosphorodithioates $\mathrm{O}\left(\mathrm{Zn}_{4}\right)\left[\mathrm{S}_{2} \mathrm{P}(\mathrm{OR})_{2}\right]_{6}\left(\text { e.g., } \mathrm{R}=\mathrm{Pr}^{\mathrm{i}}\right)^{23}$ and $\mathrm{S}\left(\mathrm{Zn}_{4}\right)\left(\mathrm{S}_{2} \mathrm{AsMe}_{2}\right)_{6}$ and $\mathrm{S}\left(\mathrm{Cu}_{4}\right)\left[\left(\mathrm{S}_{2} \mathrm{AsMe}\right)_{6}\right]^{24}$ have been characterized. Moreover, heterometallic cluster anions containing a centrohexacyclic core of six four-membered rings (hence representing centrohexaquadrane ${ }^{2}$ analogues) have been described in recent years by the groups of Clegg, ${ }^{25}$ Müller, ${ }^{26}$ and Sécheresse. ${ }^{27}$ Also, carbide 'high-nuclearity' metal carbonyl clusters such as $\mathrm{C}\left[\mathrm{Fe}_{5}(\mathrm{CO})_{15}\right]^{28}$ and cluster anions such as $\left\{\mathrm{C}\left[\mathrm{Rh}_{6}(\mathrm{CO})_{6}\left(\mu_{2}-\right.\right.\right.$ $\left.\left.\mathrm{CO})_{9}\right]\right\}^{2-29}$ may be considered topologically nonplanar polycyclic species. ${ }^{6.7}$

Although this short digression into general chemistry may not be complete, it does show that various molecular inorganic species are known bearing the centrohexacyclic (or ' $K_{5}$ ') structural unit. One reason for this may be the favourable selfaggregability of such microclusters from polar and/or charged components. In contrast to this, the generation of organic species with six rings fused in the highly spatially condensed centrohexacyclic manner requires perfect control of the stereochemistry during the synthetic (covalent) assemblage of the suitable synthons of low polarity. From an organic chemistry point of view, the fact that a centrohexacyclic molecule of type a would bear no fewer than four quaternary $\mathrm{sp}^{3}$-hybridized carbon centres bonded to another, but one and the same, quaternary carbon atom and thus represents a derivative of tetrakis(tert-butyl)methane appeared to be a challenging outset for the synthesis of a centrohexacyclic hydrocarbon.

In this paper, a full report on the three syntheses of centrohexaindane $1^{16,18,20}$ is presented and some spectroscopic and structural properties of this unusual araliphatic hydrocarbon are discussed. Furthermore, the remarkable formation of compound 1 by three-fold cyclodehydrogenation of an easily accessible tribenzotriquinacene derivative is described, and some short remarks will be made on futile attempts to generate our target compound 1. The three successful syntheses of compound 1 will be presented here in detail and contrasted with respect to the underlying strategies. Results obtained by X-ray structural analyses of compound $\mathbf{1}$, which have been performed recently, are not included in this paper, $\ddagger$ but some experimentally confirmed structural features of this unique hydrocarbon will be presented briefly.

\section{Discussion-Synthetic Concepts}

Lower Centropolyindanes. - Centrohexaindane represents the highest member of the family of regular centropolyindanes. ${ }^{30.31}$ \& Its molecular framework comprises all of its lower congeners such as the three centrotriindanes 9-11, trifuso- and tetrafuso-tetraindanes $\mathbf{1 2}$ and $\mathbf{1 3}$ (fenestrindane), respectively,

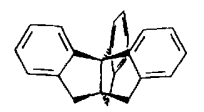

$9\left(C_{3 v}\right)$

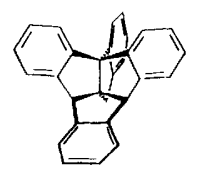

$12\left(C_{\mathrm{s}}\right)$

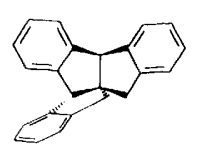

$10\left(C_{2}\right)$

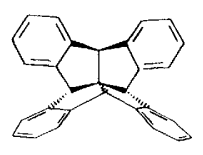

$13\left(D_{2 d}\right)$

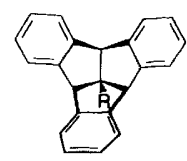

$11\left(C_{3 \mathrm{v}}\right)$

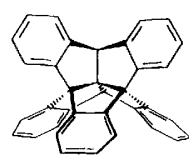

$14\left(C_{2 v}\right)$ and centropentaindane 14. Beyond the first synthesis of triptindane 9 by Thompson in $1966^{32}$ and since our first communication on this topic in $1984,{ }^{33}$ we have developed efficient synthetic routes to all these centropolyindanes in recent years. ${ }^{1,16,18.20,34-40}$ It will be shown in this paper that most of these hydrocarbons and/or closely related derivatives serve as synthetic intermediates for the construction of compound 1 following various complementary synthetic strategies.

Retrosynthesis.-Besides the C-C bonds of the six benzene rings, the $\mathrm{C}_{41} \mathrm{H}_{24}$ hydrocarbon 1 contains four central and twelve 'lateral' $\mathrm{C}-\mathrm{C}$ single bonds, corresponding to the $\mathrm{A}-\mathrm{B}$ junctions in structure a (Fig. 1). Intuitively, these are the bonds to be formed with relative ease upon construction of the centrohexaquinane core of compound 1. In other words, neither the $\mathrm{C}-\mathrm{C}$ bonds of the central neopentane core nor those of the peripheral benzene rings would be generated in the last

$\ddagger$ Repeated attempts to grow solvent-free single crystals of compound $\mathbf{1}$ enabling a most accurate $\mathrm{X}$-ray structural analysis have failed so far. Single crystals containing $\mathrm{CH}_{2} \mathrm{Cl}_{2}$ or $\mathrm{CHCl}_{3}$ have been analysed and the analysis refined to $R=0.09$ (B. Neumann, H. Bögge and P. Jutzi, University of Bielefeld, and H. Pritzkow, University of Heidelberg).

$\S$ Regular centropolyindanes comprise those congeners which contain a truly aliphatic neopentane core (see structures 1, 9-14), not allowing any $C^{x}$ atom to be fused to one of the benzo units. For irregular centropolyindanes, see ref. 31 . 


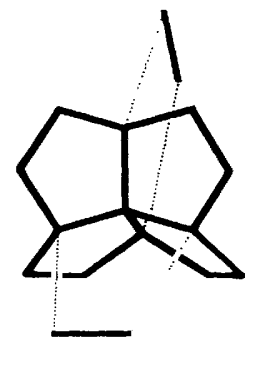

e

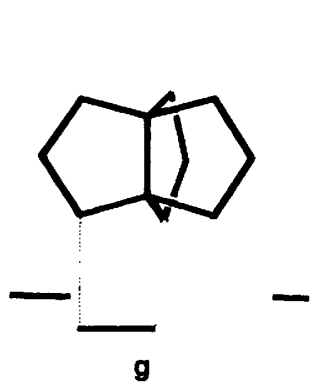

Fig. 2 Retrosynthetic pathways for the possible construction of the carbon framework of compound 1

synthetic steps, which were expected to suffer most from the mutual steric hindrance of closely adjacent groups. In fact, four retrosynthetic pathways ( $\mathbf{e}-\mathbf{h})$ have been envisaged, all of which include the cleavage of at least two pairs of lateral $\mathrm{C}-\mathrm{C}$ bonds (Fig. 2). As will be seen, this renders the actual synthetic procedures highly efficient through a number of two-fold, three-fold, and, in several cases, even four-fold $\mathrm{C}-\mathrm{C}$ bondformation processes within the same synthetic conversion.

Cleavage according to e relies on the accessibility of a suitable [5.5.5.5] fenestrane and a derivative which may be treated with two synthons that contain the $\mathrm{C}_{2}$ bridges missing from the centrohexaquinane centre. In fact, the chemistry of [5.5.5.5]fenestranes has been developed continuously during the past 20 years, ${ }^{41-45}$ and fenestrindane 13 , a stable, crystalline material promised to be a good starting point for the synthesis of compound 1 following the 'fenestrane route'. Actually, this approach led to our first synthesis of compound $1 ;{ }^{18}$ it represents the only strategy of our centrohexaindane syntheses in which the six indane units of compound 1 are annelated by a $[4+2]$ combination.

The retrosynthetic approach according to method $\mathbf{f}$ reduces the starting material to the angular (difuso-) triindane $\mathbf{1 0}$ and includes the introduction of three $\mathrm{C}_{2}$ bridges. Triindane 10, a 'broken' fenestrane, was the first centropolyindane synthesized in our laboratory; it is prepared much more easily than was the full fenestrane 13. Nevertheless, its efficient convertibility into compound 1 has been discovered only recently since it relies decisively on the selective functionalization of the benzylic and benzhydrylic $\mathrm{C}-\mathrm{H}$ bonds. In fact, this 'broken-fenestrane route' has turned out to open a remarkably short and most efficient access to compound 1 , although the three $\mathrm{C}_{2}$ bridges have to be introduced in two sequential, viz. $[3+2+1]$, annelation steps.

Retrosynthetic analysis as illustrated in method $\mathbf{g}$ represents the 'propellane route' to compound 1 . In this case, a suitable benzoannelated [3.3.3]propellane derived from the $C_{3^{-}}$ symmetrical monofuso-triindane 9 ('triptindane' ${ }^{32}$ ) is extended by three synthons providing the $\mathrm{C}_{2}$ bridges in one step only. This $[3+3]$ annelation is highly efficient, too. It is noteworthy that retrosynthetic approach $\mathrm{g}$ was chosen by Simmons III ${ }^{7,8}$ and by Paquette et al. ${ }^{10.12}$ to synthesize triether 2 and to study potential routes to centrohexaquinane 3 . Recently, the propellane route has been successfully used by us to synthesize the first tribenzocentrohexaquinane ${ }^{16}$ as well as some methylsubstituted centrohexaindanes. ${ }^{46}$

Finally, another retrosynthesis, illustrated by method $\mathbf{h}$, leads to the trifuso-triindane subunit which has again to be completed by introduction of three $\mathrm{C}_{2}$ fragments. Most synthetic possibilities according to this approach, based on various tribenzotriquinacenes of type 11, have been considered or tested, but eventually discarded. Two related approaches, however, do lead to compound 1 and are discussed below ('triquinacene route'). One of these represents a particularly short approach and corresponds to a $[3+3]$ assemblage of the six indane units of compound 1. It is based on the readily accessible centro-methyltribenzotriquinacene 11 ( $R=$ $\mathrm{Me}),{ }^{3,37}$ but the efficiency achieved so far has been very low.

Besides the propellane route $(\mathrm{g})$, two other retrosynthetic schemes (viz., $\mathbf{e}$ and $\mathbf{h}$ ) had already been envisaged by Simmons III ${ }^{8 .}$ who analysed the potential synthetic routes to centrohexaquinane 3 , but the corresponding tri- and tetraquinane derivatives, potential starting materials on routes $\mathbf{e}$ and h, appeared extremely difficult to access. Even suitable [3.3.3]propellane derivatives $(c f$. $\mathbf{g})$ required for studies aimed at the synthesis of compounds 2 and 3 turned out to be very difficult to prepare. ${ }^{8,47}$ In the case of the benzoannelated analogues, the availability of several highly stable centrotri- and centrotetra-indanes proved to be a great advantage. Hence, our successful syntheses of centrohexaindane 1 are based on the presence of the annelated benzene rings which stabilize the starting materials, reactive intermediates, and products. In the following paragraphs, the three syntheses of our target molecule 1 are discussed in detail and contrasted with respect to their respective potentials.

\section{Results}

Centrohexaindane by the 'Fenestrane Route'.- The fenestrane route to compound 1 is the longest of all syntheses presented here. Of its eleven steps, most of which have been described recently in detail, ${ }^{40}$ the first combines indane-1,3-dione 15 and dibenzylideneacetone 16 to give the double-Michael-addition product, trans-diphenylspirotriketone 17, which had been reported previously by Freimanis and co-workers ${ }^{48}$ and Ten Hoeve and Wynberg. ${ }^{49}$ Six-step synthetic sequences (in two variants ${ }^{40}$ ) then led to the all-cis-tribenzo[5.5.5.5]fenestrene 18, and two further steps furnish fenestrindane 13 (Scheme 1). Actually, this synthesis has been optimized to give compound 13 in $\sim 10 \%$ total yield from indane-1,3-dione 15 and on a several-gram scale; nevertheless, among the centropolyindanes 9-14, fenestrindane 13 is at present the most difficult one to prepare.

With its four equivalent benzhydrylic $\mathrm{C}-\mathrm{H}$ bonds, fenestrindane $\mathbf{1 3}$ is well suited for functionalization at the four 'outer' bridgehead positions. Similar to the tribenzotriquinacenes (see 11, R $=\mathrm{H}, \mathrm{Me}$, Et, see below), which have been investigated by us at the same time, ${ }^{50.51}$ compound 13 readily undergoes complete bromination of the benzhydrylic positions to give $4 b, 8 b, 12 b, 16 b$-tetrabromofenestrindane 19 in excellent yield $(93 \%)$. This halide is a stable, highly crystalline material which may be converted into a large number of interesting completely bridgehead-substituted fenestranes, ${ }^{19}$ including the corresponding tetramethyl and tetrahydroxy ${ }^{50 b .51}$ derivatives and, furthermore, heterocyclic centrohexacyclanes ${ }^{15}$ such as 6

Timmons III also envisaged the synthesis of the title compound $\mathbf{1}$, then termed 'hexabenzo- $K_{5}$ ', via triptindane $9 .{ }^{8}$ 


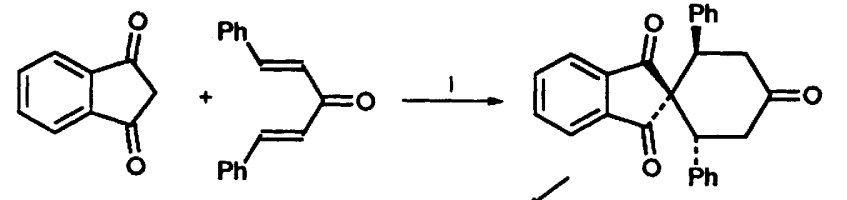

17<smiles>C[C@@]12C=C[C@H]1c1ccccc1C1c3ccccc3C2c2ccccc21</smiles>

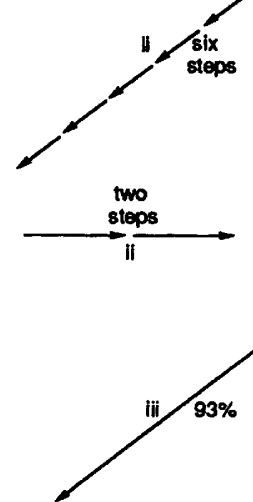

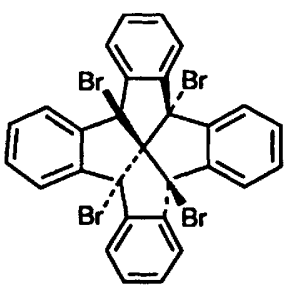

19

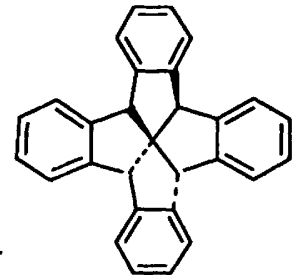

13

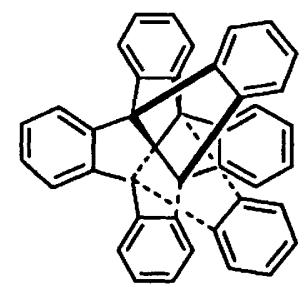

1
Scheme 1 Reagents and conditions: i, HOAc (refs. 48, 49); ii, see ref. 40; iii, $\mathrm{Br}_{2}, \mathrm{CCl}_{4}$, reflux, $h v$; iv, $\mathrm{AlBr}_{3}$, benzene, reflux, $40 \mathrm{~h}$

and 8 . The easy formation and the stability of compound 19 was surprising to us because of the fact that the two pairs of bulky bromine substituents above the two corrugated fenestrane 'faces' should suffer strong steric and probably dipolar repulsive interactions. In fact, this became evident by NMR spectrometry showing static behaviour of the two equivalent ground-state conformations. ${ }^{19}$ Accordingly, X-ray analysis of compound 19 shows ${ }^{52}$ a highly distorted, $S_{4}$-symmetrical conformation with significant flattening of the geometry at the central tetracoordinate carbon atom. ${ }^{41-45,53-57}$

The final step of the fenestrane route to compound 1 consists of a Friedel-Crafts reaction by condensation of tetrabromide 19 with two molecules of benzene. Thus, benzene solutions of tetrabromide 19 are treated with equimolar amounts of aluminium tribromide at reflux temperature; after addition of about half of the catalyst, an orange-red precipitate is observed, suggesting the formation of an ionic adduct, which has not been characterized yet. This species is redissolved upon addition of the remaining Lewis acid, and centrohexaindane 1 is obtained in high yield $(80 \%)$. The striking efficiency of this four-fold $\mathrm{C}-\mathrm{C}$ bond formation may be traced to both the remarkable 'skeletal' stability of the multiply fused fenestrane framework of substrate 19 (no fragmentation products have been found) and the 'electronic' stability of the ionic intermediates involved owing to the four annelated benzene nuclei. Speculations on the intermediacy of dicationic species bearing a doubly charged isoindene moiety have not been substantiated to date. Such species have been generated from simpler, open-chain $o$ dibenzylbenzene dihalides ${ }^{58}$ in superacidic media and may play a role in the first condensation step; however, in view of a similar condensation reaction (see $\mathbf{2 2} \longrightarrow \mathbf{1}$, Scheme 2 ), which involves the incorporation of one molecule of benzene into a $1,1^{\prime}$-dibromo[2.2']spirobiindane subunit, it appears reasonable simply to assume sequential formation, and conversion, of

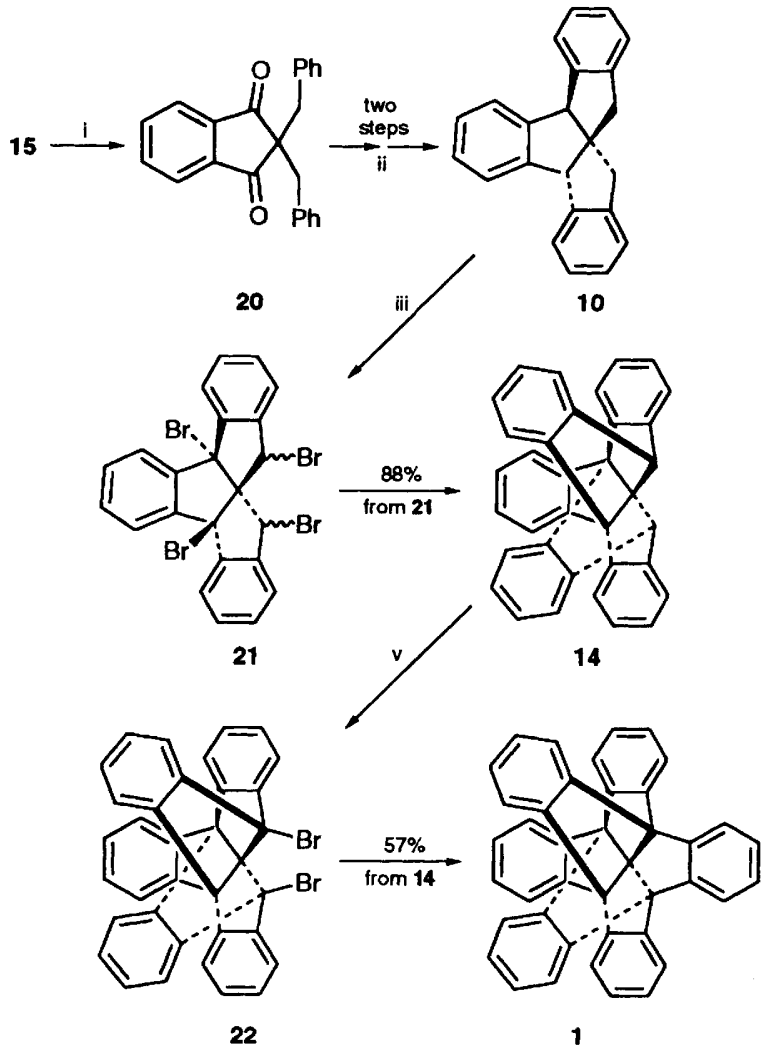

Scheme 2 Reagents and conditions: i, benzylation (see ref. 40); ii, see ref. 40 ; iii, $4 \mathrm{Br}_{2}, \mathrm{CCl}_{4}$, reflux, $h v$ (see ref. 1); iv, $\mathrm{AlBr}_{3}$, benzene, $25^{\circ} \mathrm{C}, 7$ days; $v, 2 \mathrm{Br}_{2}, \mathrm{CCl}_{4}$, reflux, $h v$ (ref. l); vi, $\mathrm{AlBr}_{3}$, benzene, $25^{\circ} \mathrm{C}$, 5 days

monocationic fenestrindane intermediates in a rather unusual kind of 'tandem' reaction. ${ }^{59}$

The fenestrane route to compound 1 represents an interesting example for the conversion of highly versatile benzoannelated fenestranes, viz. 13 and its derivatives, into a centrohexacyclic hydrocarbon, i.e. a fenestrane bridged by two other carbon $\left(\mathrm{C}_{2}\right)$ units. \| Admittedly, it suffers from the long synthetic sequence of eleven steps starting from dione $\mathbf{1 5}$ and a low overall yield $(\sim 7.5 \%)$; nevertheless, it may be used favourably in certain cases to construct centrohexaindanes with pinpoint substituent pattern.

Centrohexaindane via Centropentaindane: The 'Brokenfenestrane Route'.-As compared with complete bridgehead bromination of fenestrindane 13 and trifuso-centrotriindane 11 (see below), partial bromination of most centropolyindanes has been found unsatisfactory since bromide mixtures were obtained and the yields and stability of the desired mono- and di-bromides are low in most cases. ${ }^{50 b, 60}$ This holds also for difuso-centrotriindane 10, although this hydrocarbon bears benzylic and benzhydrylic $\mathrm{C}-\mathrm{H}$ bonds of different a priori reactivity. On the other hand, we found that 'exhaustive' bromination of all of the six aliphatic $\mathrm{C}-\mathrm{H}$ bonds of hexacycle 10 cannot be achieved either; this would generate sterically unfavourable syn-1,3-interactions in three pairs of bromine substituents ( $c f$. structure 19). Thus, the idea to generate centrohexaindane 1 by subjecting the hypothetical hexabromo derivative of compound $\mathbf{1 0}$ to a Friedel-Crafts condensation with three molecules of benzene, similar to the strategy used in the fenestrane route, was tempting but found to be futile.

$\|$ As a curiosity, the conversion $13 \longrightarrow 1$ may be considered a synthesis creating two new fenestrane units around a given fenestrane skeleton. 
Nevertheless, centrotriindane $\mathbf{1 0}$ was found to represent an excellent starting point for a new synthesis of compound 1, the 'broken-fenestrane route' (Scheme 2), which turned out to be much more efficient than the fenestrane route itself.

As described previously, ${ }^{33,40}$ centrotriindane 10 is obtained in three steps and with high yield from indane-1,3-dione 15 via diketone 20. Careful treatment of compound 10 with four mole equivalents of bromine in tetrachloromethane yields a mixture of bromotriindanes which contains predominantly the stereoisomeric tetrabromides bearing one bromine substituent at each of the four $\mathrm{C}^{\alpha}$ atoms of the neopentane core, as shown in structure 21. This follows from mass spectrometric analysis of the mixture but, most strikingly, from the subsequent conversion of tetrabromide 21 into centropentaindane 14 in excellent $(88 \%)$ yield. ${ }^{1,20}$ Alternative syntheses of this secondhighest centropolyindane have been developed as well, ${ }^{1}$ the more efficient one being a two-fold cyclodehydrogenation of benzhydryltribenzotriquinacene $11\left(\mathrm{R}=\mathrm{CHPh}_{2}\right)^{33.37}(c f$. 'triquinacene route', below). However, the bromination/condensation procedure $10 \longrightarrow \mathbf{1 4}$ is by far the most efficient synthesis of compound 14, representing a strict parallel to the incorporation of two o-phenylene bridges in the conversion $13 \longrightarrow 1$

The two bridgehead $\mathrm{C}-\mathrm{H}$ bonds remaining in centropentaindane 14 are orientated strictly 1,3-synplanar owing to the conformational rigidity of the centropentacyclic framework. ${ }^{1}$ Consequently, introduction of two substituents at these positions should markedly increase the steric strain. Nevertheless, the benzhydrylic activation of the $\mathrm{C}-\mathrm{H}$ bonds is sufficient to allow the system to pick up two bromine atoms to give compound $22 .{ }^{1}$ And in fact, in spite of its remarkable lability, this dibromide incorporates the last benzene nucleus upon treatment with aluminium tribromide in benzene solution: if the reaction is carried out at room temperature and allowed to run smoothly for several days, a remarkable $57 \%$ yield of pure centrohexaindane 1 is obtained. Overall, this improves the synthetic access to compound 1 to a seven-step protocol and, starting from indane-1,3-dione 15 , to a total yield of $40 \%$.

It may be noted at this point that, notwithstanding its close parallel to the fenestrane route, the broken-fenestrane route allows one to assemble the individual indane units of compound 1 in a completely independent manner. Again, this may be of interest if certain substituted derivatives of compound $\mathbf{1}$ have to be synthesized.

Centrohexaindane by the 'Propellane Route'.--Another, and even shorter, synthesis of compound 1 than that presented above has been developed making use of triptindane derivatives ( $c f$. structure 9) as the key intermediates for the construction of the centrohexacyclic ring system. Historically, this 'propellane route' to compound $\mathbf{1}$ was the second access route discovered ${ }^{36 h}$ and it allows the preparation of compound 1 in only six steps starting from indane-1,3-dione 15. It should be kept in mind that this route (see structure $g$ in Fig. 2) corresponds closely both to the approach used by Simmons III and Maggio ${ }^{7,8}$ and by Paquette et al. ${ }^{10,12}$ to synthesize trioxacentrohexaquinane 2 and their attempts directed toward centrohexaquinane 3.

The overall sequence of the propellane route is illustrated in Scheme 3. The crucial intermediate of this synthesis is triptindane-9,10,11-trione 24 , the $C_{3 \mathrm{v}}$-symmetrical tribenzo analogue of Conia's triketone; ${ }^{61}$ it is synthesized in four steps from dione 15 via the corresponding monoketone 23 in $60 \%$ overall yield. ${ }^{36}$

Triptindanetrione $\mathbf{2 4}$ is a remarkable and highly versatile triketone since it contains a sterically fixed triacylmethane unit. Therefore, we were much surprised to find that trione $\mathbf{2 4}$ adds up to three mole equivalents of metalorganic reagents without
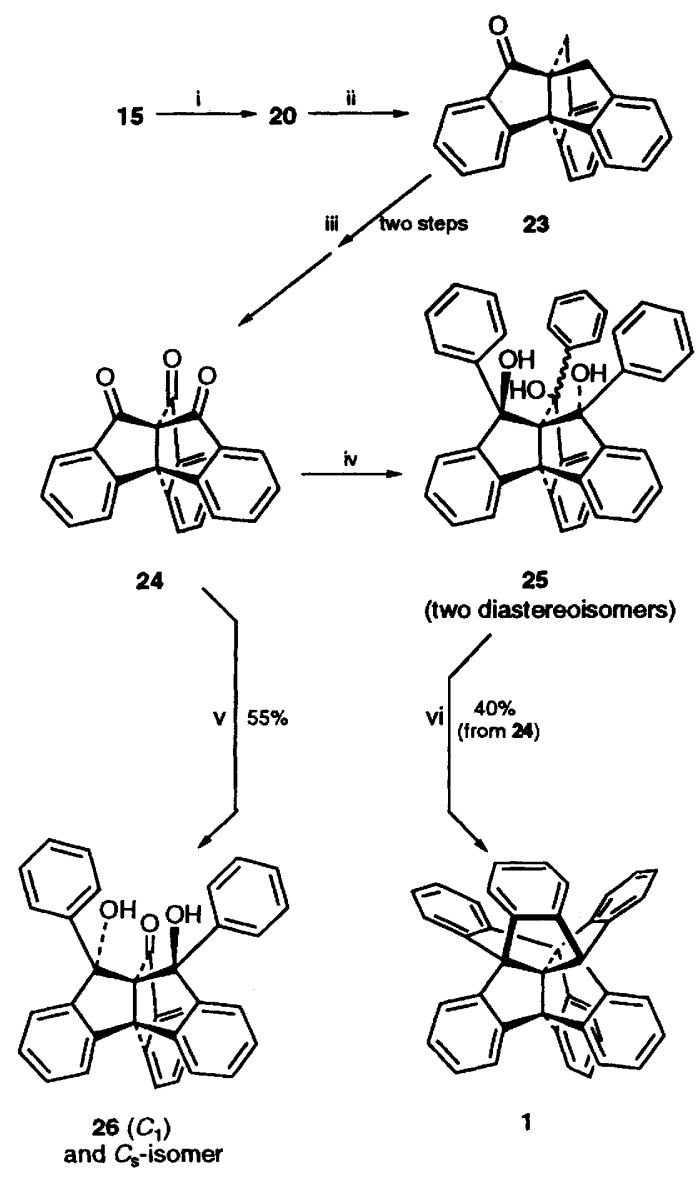

Scheme 3 Reagents and conditions: i, benzylation (see ref. 40); ii, polyphosphoric acid (ref. 36); iii, see ref. 36; iv, $\mathrm{PhLi}$ ( 20 mol equiv.), benzene- $\mathrm{Et}_{2} \mathrm{O}(85: 15)$; v, $\mathrm{PhLi}\left(4 \mathrm{~mol}\right.$ equiv.), THF- $\mathrm{Et}_{2} \mathrm{O}$-benzene $(80: 14: 6) ; \mathrm{vi}, \mathrm{H}_{3} \mathrm{PO}_{4}$, xylenes, $135^{\circ} \mathrm{C}$

cleavage of the triquinane skeleton. ${ }^{16,36}$ Addition of an excess of phenyl Grignard or phenyllithium in ether solvents [containing predominantly diethyl ether or tetrahydrofuran (THF)] leads to two-fold addition of the reagent, and the unsymmetrical keto diol $\mathbf{2 6}$ is isolated from the mixture of stereoisomers in $55 \%$ yield. Another isomer formed in $\sim 22 \%$ yield is assumed to be the $C_{\mathrm{s}}$-symmetrical diastereoisomer bearing the two phenyl substituents syn to the keto group, but this product has not been fully characterized. Products of threefold addition are not formed under these conditions, as expected with regard to the highly encumbered residual keto group in the bis-alcoholates obtained before hydrolysis. As shown recently, ${ }^{38.39} C_{\mathrm{s}}$-diindan-9-ones bearing a 10 $\beta$-phenyl substituent exhibit strong steric hindrance between the keto group and the phenyl group, the latter being orientated into the concave side of a diindane unit. Addition of two phenyl groups to the triptindane framework of trione $\mathbf{2 4}$ necessarily gives rise, in a two-fold manner, to such unfavourable steric interactions. In this respect, it is astonishing that, in spite of the unfavourable steric effects, the system does not escape by retroaldol-type cleavage of appropriate neopentane $\mathrm{C}-\mathrm{C}$ bonds after the first addition of the nucleophile (which it neither does, by Grob-type fragmentation, on the triol level of compound 25; see below). It may be noted here that indane-1,3-diones bearing two bulky substituents at C-2 do react by retro-aldol cleavage upon addition of phenyl Grignard. ${ }^{62}$ On the other hand, nonenolizable 1,3-diketones derived from $C_{\mathrm{s}}$-diindane have been found to resist retro-aldol cleavage upon addition of phenyl Grignard reagent. ${ }^{38}$ Obviously, stereoelectronic effects in the encumbered 'crown' of the triptindane framework overcome 
the tendency to form a relatively stable bridgehead 1,3-dionate anion.

In the light of these considerations, it appears all the more surprising that, in fact, triptindanetrione $\mathbf{2 4}$ undergoes even three-fold addition of phenyllithium in one synthetic step under enforced conditions. Therefore, utilization of poorly solvating media such as benzene-diethyl ether mixtures drastically enhances the reactivity of organometallic species. ${ }^{63}$ In fact, the addition of a large $(\sim 20$-fold $)$ excess of phenyllithium in diethyl ether-benzene to a suspension of the extremely poorly soluble triketone 24 in benzene yields a mixture of products which, according to mass and ${ }^{1} \mathrm{H}$ NMR analysis, contains the triol 25 as the major component. After removal of volatile by-products (mainly biphenyl), the crude product is obtained in high (96\%) yield, and TLC and MS analyses suggest the presence of two diastereoisomers which were not separated (see Experimental section). So far, no observations as to the fragmentation of the [3.3.3]propellane framework have been made. Obviously, the favourable behaviour of triketone 24 with respect to the potential drawbacks envisaged for the addition of metalorganic reagents pertains in benzene solution, and the steric hindrance of the third addition step is overrun by the high reactivity of the barely solvated reagent and/or reaction intermediates.

Upon treatment with orthophosphoric acid in xylenes at reflux temperature, the crude triol mixture $\mathbf{2 5}$ undergoes a three-fold cyclodehydration to give centrohexaindane 1 . In this manner, the centrohexacycle is isolated in $40 \%$ yield, based on triptindanetrione 24. All chemical and spectroscopic properties show that the product obtained via the propellane route is identical with those produced by the previous syntheses.

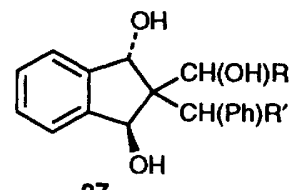

27

$\mathrm{R}, \mathrm{R}^{\prime}=\mathrm{H}$ and/or $\mathrm{Ph}$

$\mathrm{R}^{\prime}-\mathrm{R}^{\prime}=\mathrm{CH}_{2} \mathrm{CH}(\mathrm{OH}) \mathrm{CH}_{2}$<smiles>OC(c1ccccc1)C1(Cc2ccccc2)[C@H](O)c2ccccc2[C@H]1O</smiles>

29

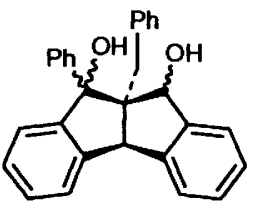

28

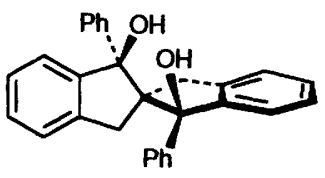

30
The three-fold cyclodehydration reaction $25 \longrightarrow 1$ deserves some special comments. First, it demonstrates the remarkable ease of the cyclization of 3-phenylpropan-1-ol groupings to indane units in the presence of other hydroxy groups in a 3position to the reacting alkanol functionality. In fact, the syntheses of many centropolyindanes rely on the two-fold cyclodehydration of 2-benzyl- and 2-benzhydrylindane-1,3diols such as 27 as a key step (e.g., 10,11 and 13). On the other hand, non-indane-type benzylic 1,3-diols such as fuso-diindanediol $28,{ }^{38}$ the 2-(hydroxybenzyl)indan-1-ol $29^{63}$ and spirodiindanediol $30^{64}$ all undergo Grob-type fragmentation under acid catalysis, whereas triol $\mathbf{2 5}$, being closely related to diol $\mathbf{2 8}$, in particular, does not. It may be speculated that the three-fold cyclodehydration of triol 25 is stereospecific, in that only the $C_{3}$-symmetrical diastereoisomer is converted into compound 1 whereas the $C_{1}$-symmetrical (unsymmetrical) one might undergo fragmentation. This hypothesis would explain the relative low yield of product 1 obtained from the crude triol mixture; however, fragmentation products could not be identified. To shed more light on this problem, the diastereoisomers would have to be isolated and subjected to attempted dehydration separately. In any case, the successful cyclodehydration of triol 25 may be ascribed to two factors: (i) the high degree of preorientation of the phenyl groups with respect to the alcohol centres, rendering the cyclization steps highly entropically favourable, and (ii) the stereoelectronic requirements for Grob fragmentation being poor in the 1,3,3'trihydroxy unit of triol $\mathbf{2 5}$ owing to the considerably reduced mobility of the mutually locked substituents at the crown of the triptindane skeleton.

On the whole, the propellane route from indane-1,3-dione 15 to centrohexaindane 1 requires only six synthetic steps and furnishes the title compound in gram amounts and in $25 \%$ overall yield. It is therefore much superior to the 'fenestrane route' but is somewhat less efficient than the 'broken-fenestrane route' due to the low solubility of trione 24 . Hence, unfortunately, a scaled-up preparation is disfavoured in the last two steps (24 $\longrightarrow 25 \longrightarrow 1$; see Experimental section). Again, the assemblage of the six indane units should allow us to introduce individually substituted benzene rings in a way which may complement the two approaches described before.

Centrohexaindane by the 'Triquinacene Route'.-A fourth access to centrohexaindane 1 , corresponding to the cleavage $h$ in the retrosynthetic view (Fig. 2), has been found very recently. Although far from being useful synthetically, this 'triquinacene route' (Scheme 4 ) represents a most remarkable approach since
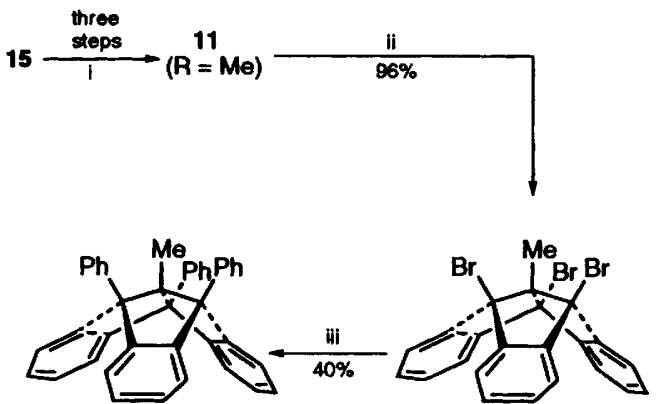

|II

31

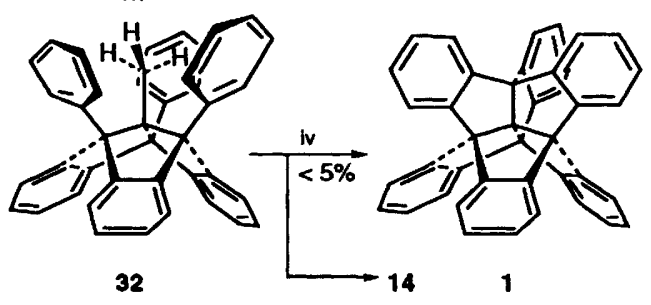

Scheme 4 Reagents and conditions: i, see ref. $37 ; \mathrm{ii}, \mathrm{Br}_{2}, \mathrm{CCl}_{4}$, reflux, $h v$; iii, $\mathrm{AlBr}_{3}$, benzene, $25^{\circ} \mathrm{C}, 3$ days; iv, $\mathrm{Pd} / \mathrm{C}, 500^{\circ} \mathrm{C}, 90 \mathrm{~min}$

it involves the catalytic activation of a methyl group, the carbon atom of which is incorporated into three newly formed cyclopentane rings. As the propellane route described above, compound 1 is obtained in only six steps starting from the readily available centro-methyl-substituted tribenzotriquinacene $11(\mathrm{R}=\mathrm{Me}){ }^{33,37}$ Bromination under standard conditions ${ }^{50}$ ( $c f$. also $13 \longrightarrow 19$ ) gives the bridgehead tribromide 31 in almost quantitative yield and as a highly stable material. ${ }^{50,65}$ Similar to tetrabromide 19, and besides a large number of other conversions of compounds 11 performed ${ }^{50}$ via tribromide 31, this multiple benzhydryl bromide may be used as an 'alkylation reagent' under Friedel-Crafts conditions. In 

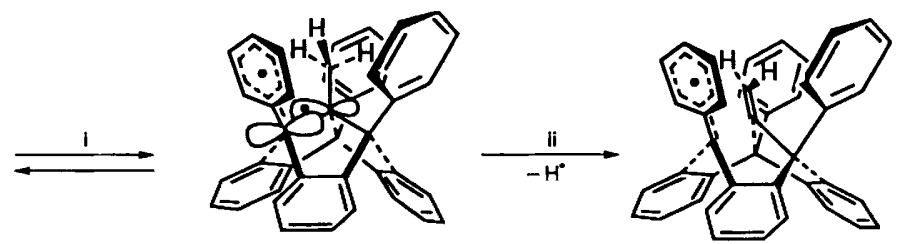

i
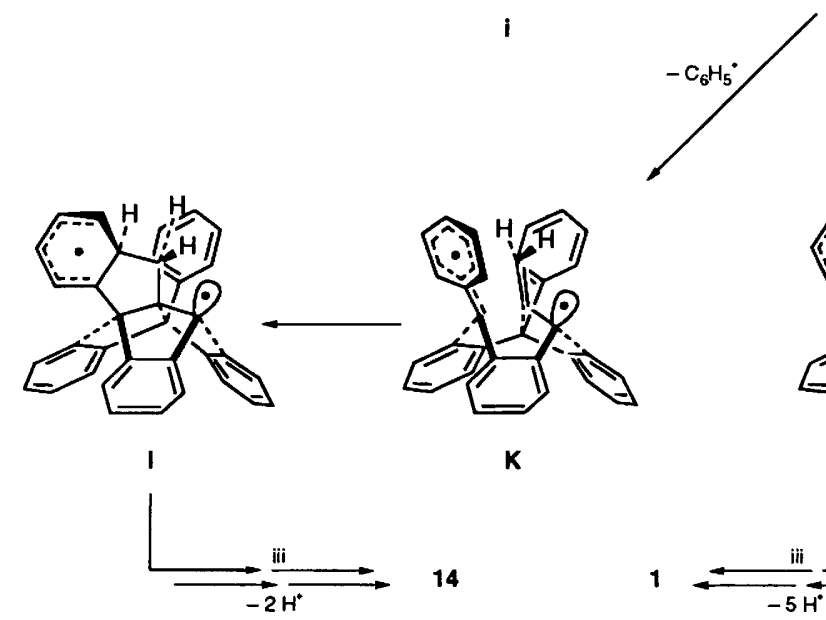

j
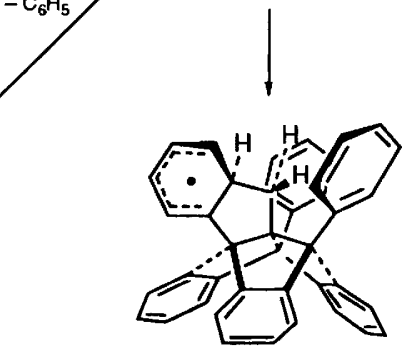

K

14

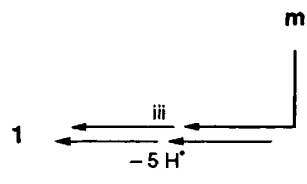

m

Scheme 5

benzene solution, catalysis by aluminium tribromide leads to the formation of the corresponding 10-methyl-1,4,7-triphenyltribenzotriquinacene 32 in moderate yield.**

It is noteworthy that four hydrocarbon substituents are locked in a strictly eclipsed orientation along the rigid triquinacene backbone of compound 32, with each of the three peripheral phenyl groups being in close vicinity of the central methyl substituent. This particular situation and the fact that the only aliphatic $\mathrm{C}-\mathrm{H}$ bonds in compound $\mathbf{3 2}$ are those of the encumbered methyl group encouraged us to subject this hydrocarbon to cyclodehydrogenation with palladium-oncharcoal at high temperatures. Whereas efficient cyclodehydrogenations are rare in araliphatic hydrocarbons and may need particular catalyst systems, as shown recently by Paquette $e t$ al., ${ }^{66}$ we found that cyclodehydrogenation of appropriate centropolyindanes may be performed favourably by utilizing conventional $\mathrm{Pd} / \mathrm{C}$ catalyst at elevated temperatures $(\sim 450-$ $550^{\circ} \mathrm{C}$ ). For example, as mentioned above, centropentaindane 14 can be synthesized in this way from centro-benzhydrylsubstituted tribenzotriquinacene $11\left(\mathrm{R}=\mathrm{CHPh}_{2}\right) .{ }^{1}$ Completion of the centrohexaindane structure by the route $\mathbf{1 4} \longrightarrow 22 \longrightarrow 1$, as described above as a part of the brokenfenestrane route, may be addressed as a (stepwise) variant of the triquinacene route (pathway h, Fig. 2).

A more direct, albeit preliminary approach to compound $\mathbf{l}$ following the triquinacene route consists of three-fold ring closure in the fully bridgehead substituted tribenzotriquinacene 32. In fact, heating of intimately mixed substrate 32 and $\mathrm{Pd} / \mathrm{C}$ $(\sim 1: 3 \mathrm{w} / \mathrm{w})$ in a steel tube at $500-550^{\circ} \mathrm{C}$ for $1.5-2.0 \mathrm{~h}$ gives a mixture of products among which centrohexaindane 1 and centropentaindane 14 are unequivocally identified by mass spectrometry and ${ }^{1} \mathrm{H}$ NMR spectroscopy. At present, the yields of compound 1 obtained by this technique have been very low (a few percent), and the bulk of products formed has not been identified. Also, it is uncertain whether optimization of this reaction is possible. At this point of development we restrict ourselves noting that the three-fold cyclodehydrogenation

** Reaction of compound 31 with anisole, however, gives the corresponding tris( $p$-methoxyphenyl)methyltribenzotriquinacene in $80 \%$ yield. ${ }^{50 b}$
$32 \longrightarrow 1$ may represent an unprecedented case in which an apparently electronically non-activated methyl group is attacked by the dehydrogenation catalyst. Being the only aliphatic group in the substrate, the methyl group appears to be activated toward $\mathrm{C}-\mathrm{H}$ bond cleavage, rather than being sterically hindered, by the presence of the three vicinal bridgehead phenyl groups.

Mechanistically, the reaction may be supported by an unusually favourable anchimeric assistance by the phenyl groups or by a purely entropic proximity effect involving the incipient methylene radical and the ortho-carbon atom being attacked. Yet a more probable mechanism relies to the thermally induced homolysis of a central bisquaternary $\mathrm{C}-\mathrm{C}$ bond ( $32 \rightleftharpoons \mathbf{i}$, Scheme 5$)$. The resulting intermediate biradical $\mathbf{i}$ is protected toward fragmentation of the triindane skeleton and will either collapse back to substrate $\mathbf{3 2}$ or undergo abstraction of a methyl hydrogen atom by the catalyst to give the triphenylmethyl radical j. This intermediate may undergo cyclization to radical $\mathbf{m}$, which is followed by several readily occurring sequential hydrogen abstraction and cyclization steps to form target compound $\mathbf{1}$. Alternatively, radical $\mathbf{j}$ may eliminate a phenyl radical to give an allyltriphenylmethyl-type biradical k; restoration of the triquinacene framework thus forming biradical l, followed by hydrogen abstraction/addition and a cyclization step, leads to centropentaindane 14. Alternative mechanisms are conceivable, and detailed investigation is required to improve the efficiency and to clarify the mechanism of this intriguing approach to compound $\mathbf{1}$.

Some too Optimistic Ideas from Pencil-and-paper Chemistry.-Cyclodehydration, a classical type of cyclization reaction, has proven a highly useful synthetic tool for the development of the centropolyindanes. All of the three syntheses of centrohexaindane 1 and even the 'dehydrogenative' triquinacene route include at least two-in the case of the propellane route even five-dehydrative cyclization processes. Thus, one may wonder whether the complex polycyclic framework of compound 1 might be accessible by still other approaches, which could be based on cyclodehydration in combination with other efficient $\mathrm{C}-\mathrm{C}$-coupling techniques such as the two-fold Michael addition and cyclodehydrogenation. Therefore, a short presentation of some attractive but, 


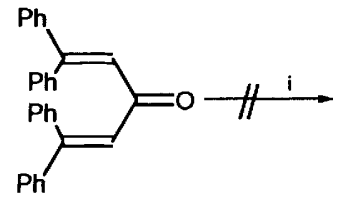

33<smiles>c1ccc(C2(c3ccccc3)OC(c3ccccc3)(c3ccccc3)c3ccccc32)cc1</smiles><smiles>CC#CCCCC</smiles>

35

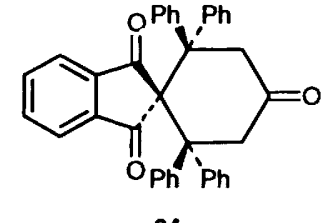

34

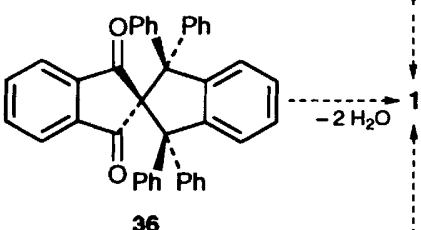

36

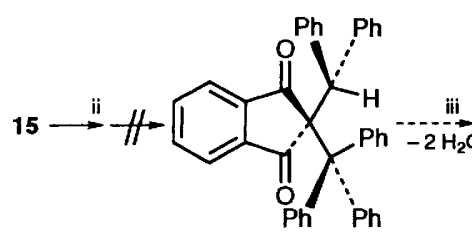

37

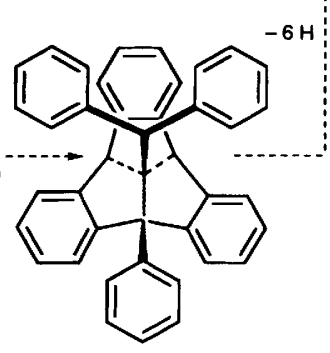

38
Scheme 6 Reagents and conditions: i, compound $15, \mathrm{H}^{+}$; ii, see ref. 36 ; iii, reduction, then $\mathrm{H}^{+}$

eventually, futile ideas for the synthesis of the title compound may be documented briefly at this point.

In analogy to the synthesis of fenestrindane 13 (Scheme 1), an attractive route to compound 1 was envisaged starting from dibenzhydrylideneacetone $33^{67}$ and indane-1,3-dione 15. Twofold Michael addition of these components was hoped to lead to the spirotrione 34 which would undergo four-fold cyclization and could be elaborated to the target hydrocarbon 1 in analogy to the sequence $\mathbf{1 7} \longrightarrow \mathbf{1 3}$. Unfortunately, the two-fold Michael addition performed under standard conditions in acetic acid $^{\mathbf{4 8 . 4 9}}$ failed, probably due to the highly unfavourable steric situation in the overcrowded spirotrione 34 .

An even shorter route was tried involving the condensation of $\alpha, \alpha^{\prime}$-dihydroxy- $\alpha, \alpha, \alpha^{\prime}, \alpha^{\prime}$-tetraphenyl-o-xylene ${ }^{68}$ and the corresponding 1,1,3,3-tetraphenylphthalan $35^{58}$ and indane-1,3dione 15. Since $\alpha, \alpha, \alpha^{\prime}, x^{\prime}$-tetraphenyl-o-xylylene dications derived from compound $\mathbf{3 5}$ have been observed in superacidic solution, ${ }^{58}$ this route could lead to the spirodione 36 , which possibly would undergo sequential multiple cyclodehydration to compound 1. Again, to date, this idea turned out to be more of a dream than reality: the phthalan $\mathbf{3 5}$ proved to be too unreactive under the conditions used. Nevertheless, this reaction may become feasible provided a suitable (superacid or Lewis acid) medium would be found which allows the system to circumvent undesired condensation paths. Notably, the hypothetical sequence $15+35 \longrightarrow 1$ would represent a tandem reaction of unmatched efficiency.

Another experimental limit was encountered when we tried to synthesize 2-benzyhydryl-2-tritylindane-1,3-dione 37, bearing two extremely bulky geminal substituents. Whereas the synthesis of 2,2-ditritylindane-1,3-dione has been claimed, ${ }^{69}$ we did not succeed in either reproducing this or preparing the slightly less sterically overcrowded dione 37. As discussed previously ${ }^{37}$ the trityl group is both too sterically demanding and, as a cation, an excellent electrofuge. In fact, this excluded the possibility to generate the benzhydryl-phenylsubstituted tribenzotriquinacene $\mathbf{3 8}$ which could have been (a)

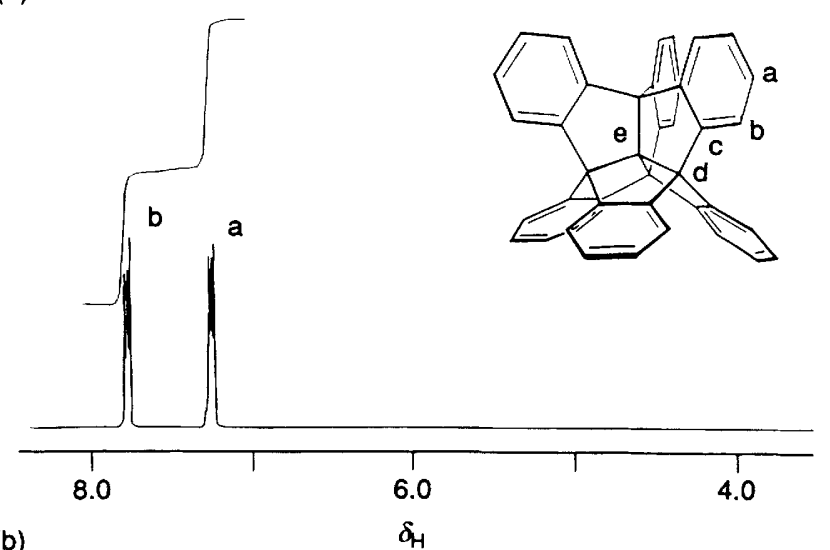

(b)

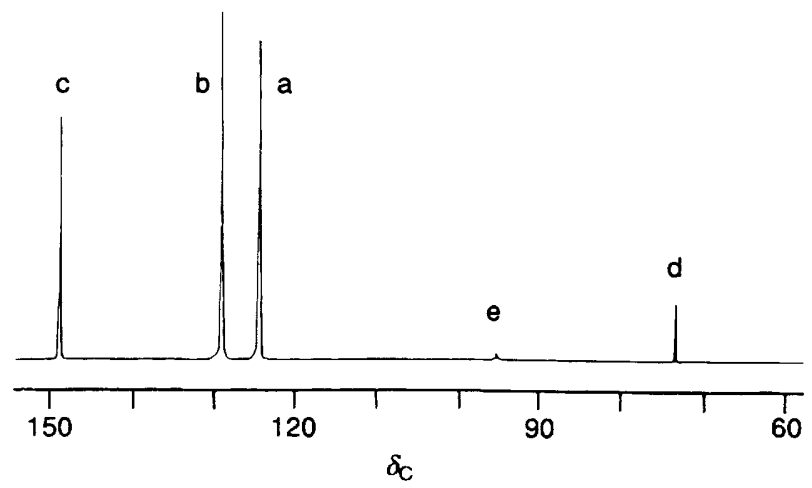

Fig. $3{ }^{1} \mathrm{H}$ NMR spectrum $\left(300 \mathrm{MHz} ; \mathrm{CDCl}_{3}\right)$ (a) and ${ }^{13} \mathrm{C}$ NMR spectrum ( $75 \mathrm{MHz} ; \mathrm{CD}_{2} \mathrm{Cl}_{2}$ ) of compound $\mathbf{1}(\mathrm{b})$

subjected to three-fold cyclodehydrogenation to give target compound 1.

Spectroscopic Properties of Centrohexaindane.-Owing to its potential role as a prototype hydrocarbon, the NMR, mass, and UV spectra of centrohexaindane 1 will be discussed here in some detail. The high molecular symmetry $\left(T_{\mathrm{d}}\right)$ of compound 1 gives rise to six equivalent indane subunits. Hence, as in indane itself, there are only five distinct resonances in the ${ }^{13} \mathrm{C}$ NMR spectrum of this $\mathrm{C}_{41} \mathrm{H}_{24}$ hydrocarbon (Fig. 3) which reflect the ipso, ortho, and meta positions of the benzene rings and those of the neopentane core. Of the latter, the central carbon atom is indicated by a singlet at $\delta_{\mathrm{C}} 95.4$ with remarkably low intensity due to inefficient magnetic relaxation. The unusually large downfield shift of this aliphatic carbon resonance may be traced to several factors: (i) the maximum possible degree of substitution at the $\alpha$ and $\beta$ positions with respect to the central atom, (ii) the high steric crowding, and (iii) the strictly in-plane orientation of the central carbon atom relative to the six aromatic rings (see below). In line with its molecular symmetry, ${ }^{1} \mathrm{H}$ NMR spectrometry of compound 1 shows only two resonances, generating an $\mathrm{AA}^{\prime} \mathbf{B B}^{\prime}$ spectrum for the six equivalent sets of benzo protons (Fig. 3). Of these, the ortho protons are distinctly more deshielded than the (peripheral) meta protons owing to the vicinity of two other arene rings of the same triphenylmethane subunit $\left(c f .{ }^{1} \mathrm{H}\right.$ NMR spectrum of compound $14^{1}$ ).

In accord with the complete mutual fusion of the six indane units, the electron-impact mass spectrum of compound 1 is dominated by the molecular ion peak at $m / z 516$ and is almost devoid of fragment-ion peaks. Besides minor signals corresponding to loss of $\mathrm{H}^{*}$ and of $\mathrm{C}_{6} \mathrm{H}_{5}{ }^{\circ}$, a minor peak at $m / z$ $258\left(<10 \%\right.$ relative to $\left.\mathrm{M}^{*+}\right)$ indicates the formation of doubly charged molecular ions.

The UV spectrum of compound $\mathbf{1}$ is very similar to those of 
the lower centropolyindanes. As found for these, there is no evidence for a significant electronic interaction between the $\pi$ systems of the adjacent aromatic rings: the lowest-energy absorption of the $\alpha$ band is observed at $\lambda_{\max }=276.5 \mathrm{~nm}$ $\left(\varepsilon \approx 5800 \mathrm{dm}^{3} \mathrm{~mol}^{-1} \mathrm{~cm}^{1}\right.$ ), corresponding to a very small $\left(\Delta \lambda_{\max } \approx+3 \mathrm{~nm}\right)$ bathochromic shift relative to indane. ${ }^{70}$ This corresponds to the spectra of other centropolyindanes containing a conformationally rigid framework, such as methyltribenzotriquinacene $11(\mathrm{R}=\mathrm{Me})$ showing $\lambda_{\max }=$ $276.5 \mathrm{~nm},{ }^{33.37}$ trifuso-centrotetraindane $12\left(\lambda_{\max }=276.0\right.$ $\mathrm{nm})^{38}$ and centropentaindane $14\left(\lambda_{\max }=276.5 \mathrm{~nm}\right){ }^{1}$ The extinction coefficients of these absorptions increase monotonically with the number of benzene rings fused in the polycyclic skeleton. Thus, the electronic excitation of compound 1 may be regarded as those of six combined but electronically isolated indane (or $o$-xylene) chromophores. It may be noted here that this holds also for those centropolyindanes which exist in two equilibrating conformations, e.g. compounds 9, 10 and 13, the only difference being that, in these cases, the slight bathochromic shift of the $\alpha$ band is not observed with these congeners. ${ }^{32-34.40}$ Similar to the centropolyindanes, benzoannelated [2.2.2] triblattanes, which contain several mutually fused 1,2-diphenylethane units instead of the diphenylmethane units of the former, do not show electronic interactions between the aromatic $\pi$ electron systems. ${ }^{71}$

Solid-state Structure of Centrohexaindane.-As mentioned above, the X-ray structural analyses of compound $\mathbf{1}$ have not yielded satisfyingly accurate results to date. Therefore, only some preliminary results concerning the mutual spatial orientation of the six indane units of compound 1 will be discussed here. As expected, the structural analyses corroborate, to a good degree of approximation, the $T_{\mathrm{d}}$ symmetry of the rigid centrohexacyclic framework of compound 1. The six $\mathrm{C}-\mathrm{C}-\mathrm{C}$ bond angles at the central carbon atom show values that are very close the ideal tetrahedral angle $\left(109.46^{\circ}\right)$, the experimentally determined average value being $\alpha=109.4( \pm 0.2)^{\circ}$. Owing to the presence of four mutually fused tribenzotriquinacene units (see structure 11, $R=H$ ), each being conformationally rigid in itself, the six five-membered rings of compound 1 do not show the usual half-envelope conformation of the indane skeleton; rather, each of the indane units is locked in the framework 1 in a completely planar conformation. As a consequence, the three $2,2^{\prime}$-spirobiindane units of compound 1 adopt linear conformations stretched along the $C_{2 \mathrm{v}}$ axes, and they are orientated perfectly orthogonally to each other, i.e. $\beta=90.1 \pm 0.1^{\circ}[$ Fig. 4(a)]. For the same reason, the four triptindane units (structure 9) in compound 1 are fixed in strict $C_{3 v}$-symmetrical conformations, that is with arene-arene dihedral angles $\gamma=120.0 \pm 0.4^{\circ}$ [Fig. 4(b)]. This corresponds to the most unfavourable transition state for the 'concerted' conformational conversion of triptindane $9 .{ }^{72}$ Similarly, the three fenestrindane units (structure 13) interfused in compound 1 are locked in a perfect $D_{2 \mathrm{~d}}$ conformation, again corresponding to the most unfavourable transition state of the concerted interconversion of the $S_{4}$-symmetrical conformers of moiety 13. ${ }^{19,34,52}$ These structural features provide the first experimental proof for the $T_{\mathrm{d}}$ symmetry of the carbon framework of a centrohexaquinacene derivative in its conformational ground state. This result was predicted for the parent centrohexaquinacene 4 by $\operatorname{Ermer}^{13}$ on the basis of forcefield calculations.

Conclusions.-Centrohexaindane 1, a unique polycyclic hydrocarbon with $T_{d}$ molecular symmetry and topologically nonplanar $\left(K_{5}\right)$ molecular skeleton, bears six indane units mutually fused at a common neopentane core and stretched along the six directions of space. It was synthesized by three (a)

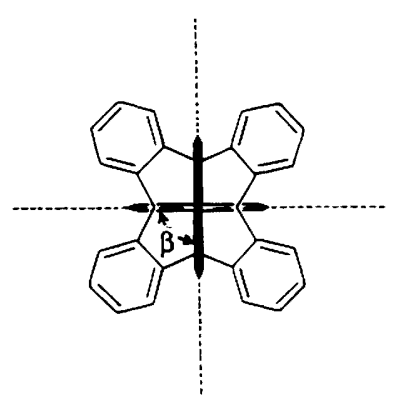

Fig. 4 Orientation of the six indane units in compound 1, as viewed along a spirobiindane $C_{2 \mathrm{v}}$ axis (a) and along a triptindane $C_{3 \mathrm{v}}$ axis (b, see text)

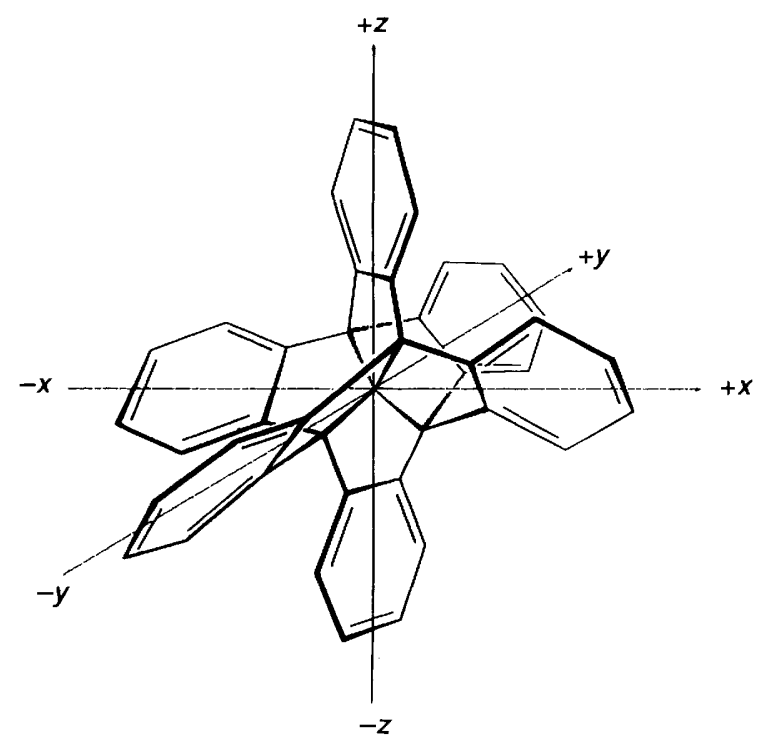

Fig. 5 Fenestrane route $-X+X /-Y+Y /-Z+Z$; propellane route $-X /-Y-Z /+X+Y+Z$; broken-fenestrane route $-X /-Y+Y /-Z$ $+Z /+X ;$ triquinacene route $-X /-Y+Z /+X+Y-Z$

independent and complementary routes, and its formation was observed by another approach which is being further developed at present. The syntheses including the latter approach are contrasted in Fig. 5 by sketching the framework of compound 1 along the axes of the three-dimensional space and denoting the synthetic sequence according to the site of the individual indane units in the coordinate system. Starting with the indane unit of indane-1,3-dione $\mathbf{1 5}$ at the negative moiety of the $x$ axis (denoted by $-X$ ), the fenestrane route, for example, continues by adding another indane at $+X$, then by incorporating two indanes at $-Y$ and $+Y$ and, finally, those at $-Z$ and $+Z$.

Interestingly, the fenestrane route appears to be the simplest route but has turned out to be the longest and least efficient one (11 steps, $7.5 \%$ total yield) whereas the formally least straightforward access to compound 1, viz. the brokenfenestrane route, is most efficient (seven steps, $40 \%$ yield). The two remaining approaches, the propellane and the triquinacene route, both involving the symmetrical incorporation of three indane units, are conceptually the shortest since they comprise only six steps. However, whereas the propellane route is only somewhat less efficient (total yield $25 \%$ ), the triquinacene route has furnished only low yields $(<5 \%)$ to date; more work is required to improve this approach

In fact, our efforts to prepare compound 1 on the basis of lower centropolyindanes proved successful since three factors facilitated the synthesis of the hexabenzo analogue of the elusive centrohexaquinane 3: (i) the applicability of the 
principles of electrophilic aromatic substitution chemistry, in particular of cyclodehydration of $\gamma$-functionalized alkylbenzenes; (ii) the generally experienced greater stability of areneannelated substrates and also of the corresponding transient species as compared with their olefinic (non-benzoannelated) counterparts, and (iii) the tendency of condensed aromatic molecules to give readily crystallizing materials. All of these three aspects turned out to be, in fact, of great importance here, and it is hoped that experience gathered by these investigations will help to pave the way to a goal hidden in the background: centrohexaquinane $3 .{ }^{16}$

\section{Experimental}

General.-Mps (uncorrected): Büchi 512 and Electrothermal melting point apparatus. IR: Perkin-Elmer 841. UV: Beckman model 25. ${ }^{1} \mathrm{H}$ NMR: Bruker AM 300. ${ }^{13} \mathrm{C}$ NMR: Bruker AM 300 ( $J$-modulated spin-echo experiments). $J$-Values are given in Hz. MS: Finnigan MAT 311 A, Finnigan CH 5 DF, Fisons VG Autospec; all run in the EI mode, $70 \mathrm{eV}$. Combustion analyses: Perkin-Elmer 240 and LECO CHNS-932 Analysator. MPLC: Besta E 100 and Besta UV 1; column dimensions $25 \times 250 \mathrm{~mm}$ and $25 \times 500 \mathrm{~mm}$; eluent $6 \mathrm{~cm}^{3}$ $\min ^{-1}$; Kieselgel LiChroprep Si 60, 40-60 $\mu \mathrm{m}$ (Merck), Matrex LC $60,20-45 \mu \mathrm{m}$ and 35-70 $\mu \mathrm{m}$ (Grace). TLC: Kieselgel 60 $\mathrm{F}_{254}$ on $\mathrm{Al}$ foil (Merck).

Centrohexaindane 1 from Compound 13 (Fenestrane Route).-4b,8b,12b,16b-Tetrabromo-4b,8b,12b,16b-tetrahydrodibenzo $[\mathrm{a}, \mathrm{f}]$ dibenzo $[2,3: 4,5]$ pentaleno $[1,6-\mathrm{cd}]$ pentalene

(Tetrabromofenestrindane 19). A warm suspension of fenestrindane $13^{40}(368 \mathrm{mg}, 1.00 \mathrm{mmol})$ in tetrachloromethane $\left(100 \mathrm{~cm}^{3}\right)$ was stirred while a $1.00 \mathrm{~mol} \mathrm{dm}{ }^{-3}$ solution of bromine in the same solvent $\left(4.00 \mathrm{~cm}^{3} ; 4.00 \mathrm{mmol}\right)$ was added within 2 min. Upon addition of the first half of the reagent intense formation of hydrogen bromide was observed and the mixture became homogeneous. Continued addition gave a precipitate, and the reaction was completed by irradiation of the mixture with a $500 \mathrm{~W}$ photolamp. The solvent was removed under reduced pressure and the lemon-yellow residue was recrystallized from toluene to give tetrabromide $19(635 \mathrm{mg}, 93 \%)$ as needles, mp $341^{\circ} \mathrm{C}$ (decomp.); $v_{\max }(\mathrm{KBr}) / \mathrm{cm}^{-1} 3069,3040$, $1466,1260,1161,1095,1022,1015,877,760,735$ and 652; $\delta_{\mathrm{H}}\left(300 \mathrm{MHz} ; \mathrm{CDCl}_{3} ; \mathrm{Me}_{4} \mathrm{Si}\right) \mathrm{ABCX}$ spin system $7.95(4 \mathrm{H}, \mathrm{d}$, ${ }^{3} J 7.4$ and $7.54-7.45(12 \mathrm{H}, \mathrm{m}) ; \delta_{\mathrm{C}}\left(75 \mathrm{MHz} ; \mathrm{CDCl}_{3} ; \mathrm{Me}_{4} \mathrm{Si}\right)$ 145.5 and 140.5 (quat. C), 130.3, 130.0, 127.2 and 123.2 (tert. C), 87.7 (q, C-16d) and 72.3 (q); $m / z 601,603,605$ and 607 $\left(25 / 76 / 73 / 26 \%,[\mathrm{M}-\mathrm{Br}]^{+}\right), 522,524$ and $526(16 / 35 / 22,[\mathrm{M}$ $\left.-2 \mathrm{Br}]^{\circ+}\right), 443$ and $445\left(37 / 43,[\mathrm{M}-3 \mathrm{Br}]^{+}\right), 365(40), 364$ (95), 363 (100), 262.5 (2) and 262 (4) (Found: C, 51.7; H, 2.3. $\mathrm{C}_{29} \mathrm{H}_{16} \mathrm{Br}_{4}$ requires $\mathrm{C}, 50.9 ; \mathrm{H}, 2.35 \%$ ).

\section{$4 \mathrm{~b}, 12 \mathrm{~b}\left[1^{\prime}, 2^{\prime}\right]: 8 \mathrm{~b}, 16 \mathrm{~b}\left[1^{\prime \prime}, 2^{\prime \prime}\right]$ Dibenzenodibenzo $[\mathrm{a}, \mathrm{f}]$ dibenzo-} [2,3:4,5]pentaleno[1,6-cd]pentalene, Centrohexaindane 1. Tetrabromofenestrindane $19(500 \mathrm{mg}, 730 \mu \mathrm{mol})$ was dissolved in warm anhydrous benzene $\left(100 \mathrm{~cm}^{3}\right)$ and a 100 mmol dm${ }^{-3}$ solution of aluminium tribromide in benzene $(10$ $\mathrm{cm}^{3}, 1.0 \mathrm{mmol}$ ) was added dropwise within $2 \mathrm{~h}$ at $40^{\circ} \mathrm{C}$. An orange-red complex was formed, which redissolved after complete addition of the reagent. The solution was heated to slight reflux for $40 \mathrm{~h}$ and then was hydrolysed by addition of water. The mixture was extracted with dichloromethane, the combined extracts were dried with sodium sulfate, and the solvent was removed under reduced pressure to leave a yellow solid, which was recrystallized from xylenes $\left(20 \mathrm{~cm}^{3}\right)$ to give the title compound $1(300 \mathrm{mg}, 80 \%)$ as needles, $\mathrm{mp}>420^{\circ} \mathrm{C}$. Large crystals of compound 1 may be obtained from chloroformmethanol solutions using the vapour-diffusion technique
$\left(\mathrm{MeOH} \longrightarrow \mathrm{CHCl}_{3}\right) ; v_{\max }(\mathrm{KBr}) / \mathrm{cm}^{-1} 3059,3018,1466,1157$, 1074,752 and $618 ; \delta_{\mathrm{H}}\left(300 \mathrm{MHz} ; \mathrm{CDCl}_{3} ; \mathrm{Me}_{4} \mathrm{Si}\right) \mathrm{AA}^{\prime} \mathrm{BB}^{\prime}$ spin system $7.79(12 \mathrm{H})$ and $7.29(12 \mathrm{H})$ [see Fig. $3(\mathrm{a})$ ]; $\delta_{\mathrm{C}}(75 \mathrm{MHz}$; $\mathrm{CD}_{2} \mathrm{Cl}_{2} ; \mathrm{Me}_{4} \mathrm{Si}$ ) 148.2 (quat. C), 128.5, 123.9 (tert. C), 95.0 (q, C-16d) and 73.0 (q, C-4b, -8b, -12b and C-16b) [see Fig. (3b)]; $m / z 516\left(100 \%, \mathbf{M}^{\cdot+}\right), 515(12), 439(3)$ and $258\left(4, \mathrm{M}^{2+}\right)$; $\lambda_{\text {max }}\left(\right.$ heptane, c $\left.4 \times 10^{-5} \mathrm{~mol} \mathrm{dm}^{-3}\right) / \mathrm{nm} 276.5\left(\varepsilon / \mathrm{dm}^{3} \mathrm{~mol}^{-1}\right.$ $\mathrm{cm}^{-1}$ 5800), 269 (5000), 263 (3000) and 257sh (Found: C, 94.9; $\mathrm{H}, 5.1 . \mathrm{C}_{41} \mathrm{H}_{24}$ requires $\mathrm{C}, 95.3 ; \mathrm{H}, 4.7 \%$ ).

Centrohexaindane 1 from Compound 22 (Broken-fenestrane Route).-Dibromocentropentaindane 22, a labile material readily decomposing at ambient temperature under air, was prepared from centropentaindane $14(442 \mathrm{mg}, 1.00 \mathrm{mmol})$ and was recrystallized from toluene under argon as described previously. ${ }^{1}$ The product obtained in this way was redissolved in anhydrous benzene $\left(50 \mathrm{~cm}^{3}\right)$ under argon, and the solution was stirred at room temperature while a solution of aluminium tribromide ( $330 \mathrm{mg}, 1.24 \mathrm{mmol})$ in anhydrous benzene $\left(20 \mathrm{~cm}^{3}\right)$ was added dropwise within $1 \mathrm{~h}$. Stirring of the orange-red mixture under argon was continued for 3-5 days while the reaction was monitored by TLC. The mixture was hydrolysed by addition of water and extracted with dichloromethane; the combined extracts were dried with sodium sulfate, and the solvent was removed under reduced pressure. The yellowbrown residue was redissolved in a little chloroform and the solution was filtered through a pad of silica gel. The residue obtained after evaporation of the solvent was recrystallized from xylenes to give the title compound $1(290 \mathrm{mg}, 57 \%)$, as identified by identical ${ }^{1} \mathrm{H}$ NMR and mass spectra with the material obtained from compound $\mathbf{1 3}$ (see above).

Centrohexaindane 1 from Trione 24 (Propellane Route).10,11-Dihydroxy-10,11-diphenyl-9H,10H-4b,9a- $([1,2]$ benzenomethano)indeno[1,2-a]inden-9-one 26. A suspension of triptindane-9,10,11-trione $24(336 \mathrm{mg}, 1.00 \mathrm{mmol})$ in anhydrous THF $\left(20 \mathrm{~cm}^{3}\right)$ was stirred under nitrogen while a $0.85 \mathrm{~mol}$ $\mathrm{dm}^{-3}$ solution of phenyllithium in diethyl ether-benzene $\left(7: 3 ; 5.00 \mathrm{~cm}^{3}, 4.25 \mathrm{mmol}\right)$ was added by syringe. After the addition was complete, the mixture started to warm to reflux temperature and turned red. It was stirred for $15 \mathrm{~min}$, allowed to cool, and was then hydrolysed by addition of water to give a colourless mixture. Aq. ammonium chloride $\left(20 \mathrm{~cm}^{3}\right)$ was added, the mixture was extracted with diethyl ether, and the combined extracts were dried with sodium sulfate. Evaporation of the solvent gave a solid residue, which was subjected to MPLC [silica gel; $\mathrm{CH}_{2} \mathrm{Cl}_{2}-\mathrm{EtOAc}(98: 2)$ ] to remove byproducts (mainly biphenyl). The first eluted isomer (26) was obtained pure $(270 \mathrm{mg}, 55 \%), \mathrm{mp} 246^{\circ} \mathrm{C}$; the second fraction (110 mg, $22 \%$ ) represented mainly another isomer, $\mathrm{mp} 250^{\circ} \mathrm{C}$ (see Discussion section). Isomer $\mathbf{2 6}$ was assigned the unsymmetrical stereoorientation of the phenyl groups; $v_{\max }(\mathrm{KBr})$ $\mathrm{cm}^{-1} 3825,3381,3065,3029,1703$ and $756 ; \delta_{\mathrm{H}}(300 \mathrm{MHz}$; $\left.\mathrm{CDCl}_{3} ; \mathrm{Me}_{4} \mathrm{Si}\right) 7.85\left(3 \mathrm{H}, \mathrm{d},{ }^{3} J\right.$ 7.6), 7.50-7.52 (4 H, m), $7.34\left(2 \mathrm{H}, \mathrm{t},{ }^{3} J 7.6\right), 6.90-7.18(12 \mathrm{H}, \mathrm{m}), 6.79\left(1 \mathrm{H}, \mathrm{d},{ }^{3} J 7.6\right)$ and $4.79(2 \mathrm{H}$, br s, OH $) ; m / z 474\left(50 \%,\left[\mathrm{M}-\mathrm{H}_{2} \mathrm{O}\right]^{\circ}\right), 446$ (12), 340 (11), 339 (34), 265 (10), 263 (19), 105 (100), 78 (12), 77 (86) and $76(10)$ (Found: $\mathrm{C}, 85.2 ; \mathrm{H}, 4.85 . \mathrm{C}_{35} \mathrm{H}_{24} \mathrm{O}_{3}$ requires $\mathrm{C}$, $85.35 ; \mathrm{H}, 4.9 \%$ ).

9,10,11-Triphenyl-9H,10H-4b,9a-([1,2]benzenomethano)indeno $[1,2-\mathrm{a}]$ indene-9,10,11-triol 25 (Mixture of Isomers).-A suspension of triptindane-9,10,11-trione $\mathbf{2 4}(3.36 \mathrm{~g}, 10.0 \mathrm{mmol})$ in anhydrous benzene $\left(250 \mathrm{~cm}^{3}\right)$ was stirred under nitrogen while a $0.85 \mathrm{~mol} \mathrm{dm}^{3}$ solution of phenyllithium in benzenediethyl ether $\left(3: 7 ; 250 \mathrm{~cm}^{3}, 212 \mathrm{mmol}\right)$ was added through a dropping funnel. The suspension was held at $40^{\circ} \mathrm{C}$, and the triketone dissolved slowly while some lithium hydroxide 
precipitated $c a .1 \mathrm{~h}$ after the addition was complete. Stirring was continued for $5 \mathrm{~h}$ at $40^{\circ} \mathrm{C}$ before the mixture was allowed to cool to room temperature and then hydrolysed by addition of water. The organic layer was diluted with diethyl ether and separated, the aqueous layer was extracted with the same solvent, and the combined organic solutions were washed with water, and dried with sodium sulfate. Removal of the solvent gave a residue, from which biphenyl was distilled off in a Kugelrohr apparatus at $100^{\circ} \mathrm{C}(15 \mathrm{~Pa})$. A brownish material $(5.47 \mathrm{~g}, 96 \%)$ was obtained, showing only one spot on TLC, $R_{\mathrm{f}}$ $0.25\left[\mathrm{CH}_{2} \mathrm{Cl}_{2}-\operatorname{EtOAc}(95: 5)\right]$. A solution of this crude product $(300 \mathrm{mg})$ in ethyl acetate $\left(\mathrm{ca} .10 \mathrm{~cm}^{3}\right)$ was filtered through silica gel and further subjected to MPLC $\left[\mathrm{CH}_{2} \mathrm{Cl}_{2}-\mathrm{EtOAc}(85: 15)\right.$; $t_{\mathrm{R}}(1) 42 \mathrm{~min}, t_{\mathrm{R}}(2) 58 \mathrm{~min}$ ] which showed it to contain two isomers. Both compounds showed identical mass spectra; $v_{\max }(\mathrm{KBr}) / \mathrm{cm}^{-1} 3556,3070,1058,703$ and $614 ; \mathrm{m} / \mathrm{z} 570(1 \%$, $\left.\mathrm{M}^{*^{+}}\right), 552\left(36,\left[\mathrm{M}-\mathrm{H}_{2} \mathrm{O}\right]^{++}\right), 553(16), 475(17), 458(11), 457$ (9), $105(100), 106(9), 91(14)$ and $77(39)$.

Centrohexaindane 1. The crude mixture of isomeric 9,10,11triphenyltriptindane-9,10,11-triols $25(9.60 \mathrm{mmol})$ obtained as described above was dissolved in xylenes $\left(250 \mathrm{~cm}^{3}\right)$ (Merck, p.a.), orthophosphoric acid $\left(85 \%, 5 \mathrm{~cm}^{3}\right)$ was added, and the mixture was stirred and heated to reflux in a reactor equipped with a Thiele-Pape extractor filled with pre-dried molecular sieves $(4 \AA)$. The cyclodehydration was completed after $25-30 \mathrm{~h}$, as monitored by TLC. The mixture was allowed to cool, and the organic solution was decanted from the oily residue, washed with aq. sodium hydrogen carbonate, and dried with sodium sulfate. Removal of the solvent gave a brownish residue, which was redissolved in some chloroform and the solution was filtered through a pad of silica gel. Evaporation of the solvent yielded pure compound $1(1.98 \mathrm{~g}, 40 \%)$ as crystals, the spectroscopic data of which were identical with those given above.

Centrohexaindane 1 from Compound 11 (Triquinacene Route)-4b,8b,12b-Tribomo-12d-methyl-4b,8b,12b,12d-tetrahydrodibenzo $[2,3: 4,5]$ pentaleno $[1,6-\mathrm{ab}]$ indene, $\quad$ 1,4,7-Tribromo-10-methyltribenzotriquinacene 31. To a stirred solution of methyltribenzotriquinacene $11(\mathrm{R}=\mathrm{Me})(294 \mathrm{mg}, 1.00$ $\mathrm{mmol})$ in slightly heated anhydrous tetrachloromethane (50 $\mathrm{cm}^{3}$ ) was slowly added a $1.00 \mathrm{~mol} \mathrm{dm} \mathrm{dm}^{-3}$ solution of bromine in the same solvent $\left(3.30 \mathrm{~cm}^{3}, 3.30 \mathrm{mmol}\right)$. The mixture is irradiated with a $500 \mathrm{~W}$ photolamp. Initially, the reaction proceeded rapidly as indicated by efficient absorption of the reagent and strong effervescence of the solution by the hydrogen bromide evolved. After the reaction had slowed down, irradiation was continued for $15 \mathrm{~min}$ at reflux temperature. The product began to precipitate as fine needles after two-thirds of the reagent solution had been added. Finally, the solvent and excess of bromine were removed, and the residue was recrystallized from toluene $\left(100 \mathrm{~cm}^{3}\right)$ to yield tribromide $31(509 \mathrm{mg}, 96 \%)$ as extremely (up to $4 \mathrm{~cm}$ ) long needles, mp $340^{\circ} \mathrm{C}$ (decomp.); $v_{\max }(\mathrm{KBr}) / \mathrm{cm}^{-1}$ 3073, 3033, $2988,1472,1459,1271,1214$ and $750 ; \delta_{\mathrm{H}}\left(300 \mathrm{MHz} ; \mathrm{CDCl}_{3}\right.$; $\mathrm{Me}_{4} \mathrm{Si} \mathrm{AA}^{\prime} \mathrm{BB}^{\prime}$ spin system $7.70(6 \mathrm{H}), 7.32(6 \mathrm{H})$ and $2.32(3 \mathrm{H}$, s); $\delta_{\mathrm{C}}\left(75 \mathrm{MHz} ; \mathrm{CDCl}_{3} ; \mathrm{Me}_{4} \mathrm{Si}\right) 143.4$ (quat. C), 130.4 and 125.6 (tert. C), 80.2 (q), 75.1 (q, C-12d) and 36.9 (s); $m / z 449,451$ and $453\left(49 / 100 / 49 \%,[\mathrm{M}-\mathrm{Br}]^{+}\right), 369$ and $371(15 / 17,[\mathrm{M}-(\mathrm{Br}$, $\left.\left.\mathrm{HBr}^{+}\right]^{+}\right), 291(70), 289(46), 276(30), 274(15), 184.5$ and 185.5 $\left(13 / 13,[\mathrm{M}-(\mathrm{Br}, \mathrm{HBr})]^{2+}\right)$ and $145(26)$ (Found: $\mathrm{C}, 52.85 ; \mathrm{H}$, 2.8. $\mathrm{C}_{23} \mathrm{H}_{15} \mathrm{Br}_{3}$ requires $\mathrm{C}, 52.0 ; \mathrm{H}, 2.85 \%$ ).

12d-Methyl-4b,8b,12b-triphenyl-4b,8b,12b,12d-tetrahydrodibenzo[2,3:4,5]pentaleno[1,6-ab]indene, 10-Methyl-1,4,7triphenyltribenzotriquinacene 32.-Tribromide $31(530 \mathrm{mg}$, $1.00 \mathrm{mmol}$ ) was dissolved in anhydrous benzene $\left(25 \mathrm{~cm}^{3}\right)$ by slight heating. The solution was stirred and allowed to cool to room temperature, and a solution of aluminium tribromide $(1.07 \mathrm{~g}, 4.00 \mathrm{mmol})$ in benzene $\left(5 \mathrm{~cm}^{3}\right)$ was added. The mixture turned red-brown and was stirred for 3 days at room temperature. After addition of water $\left(10 \mathrm{~cm}^{3}\right)$ the mixture was extracted with dichloromethane, and the combined extracts were dried with sodium sulfate. Evaporation of the solvent gave a yellow-brown oil, from which a powder precipitated upon careful addition of ethyl acetate. This material was separated and washed several times with hot ethyl acetate. Recrystallization from xylenes yielded hydrocarbon $32(203 \mathrm{mg}, 40 \%)$ as crystals, mp $396^{\circ} \mathrm{C} ; v_{\max }(\mathrm{KBr}) / \mathrm{cm}^{-1} 3026,2976,2932,1494$, $1481,1446,1033,748$ and $699 ; \delta_{\mathrm{H}}\left(300 \mathrm{MHz} ; \mathrm{CDCl}_{3} ; \mathrm{Me}_{4} \mathrm{Si}\right)$

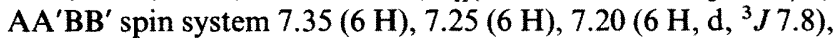
$7.15\left(3 \mathrm{H}, \mathrm{d},{ }^{3} J 6.9\right), 7.05\left(6 \mathrm{H}, \mathrm{d},{ }^{3} J 7.0\right)$ and $-0.28(3 \mathrm{H}, \mathrm{s})$; $\delta_{\mathrm{C}}\left(75 \mathrm{MHz} ; \mathrm{CDCl}_{3} ; \mathrm{Me}_{4} \mathrm{Si}\right.$ ) 148.9 and 146.9 (quat. C), 130.2, $128.0,127.4,126.2$ and 125.5 (tert. C), 77.8 (q, C-12d), 74.1 (q) and $25.7(\mathrm{~s}) ; m / z 522\left(79 \%, \mathrm{M}^{*+}\right), 445\left(100,\left[\mathrm{M}-\mathrm{C}_{6} \mathrm{H}_{5}\right]^{+}\right)$, $367(21), 339$ (5), 289 (6), 261 (6) and 222.5 (2) (Found: C, 93.4; $\mathrm{H}, 5.75 . \mathrm{C}_{41} \mathrm{H}_{30}$ requires $\mathrm{C}, 94.2 ; \mathrm{H}, 5.8 \%$ ).

Cyclodehydrogenation of Compound 32.-Finely powdered 10-methyl-1,4,7-triphenyltribenzotriquinacene 32 (100 mg, 190 $\mu \mathrm{mol})$ was intimately mixed with palladium-on-charcoal (300 $\mathrm{mg} ; 10 \% \mathrm{Pd}$; Merck) in a mortar. The mixture was poured to fill a cylindrical steel bomb $\left(160 \times 16 \mathrm{~mm}\right.$, inner volume $\left.8 \mathrm{~cm}^{3}\right)$, which was hermetically closed and then carefully introduced into an electric oven preheated to $500 \pm 20^{\circ} \mathrm{C}$. After being heated at this temperature for $90 \mathrm{~min}$, the cylinder was allowed to cool, and the reaction product was extracted with chloroform to leave a solid residue ( $\sim 10 \mathrm{mg})$, which was analysed by mass and ${ }^{1} \mathrm{H}$ NMR spectrometry. The presence of compounds 1 and 14 besides a majority of unidentified products was revealed by their characteristic molecular (base) peaks at $\mathrm{m} / z 516$ and $\mathrm{m} / \mathrm{z}$ $442(\sim 1: 1)$ and by the characteristic AA $^{\prime}$ BB' $^{\prime}$ spectrum of compound 14 at $\delta 7.66,7.16$ and 5.08. The mass spectrum also displayed a distinct peak at $\mathrm{m} / \mathrm{z} 368$ (suggesting the presence of centrotetrindane 12) and another one at $\mathrm{m} / \mathrm{z} 592$ (indicating a product formed by addition of $\mathrm{C}_{6} \mathrm{H}_{4}$ to compound 1 ).

\section{Acknowledgements}

We are grateful to Professor Hans-Friedrich Grützmacher for support of our work and to Mrs. Beate Neumann, Dr. Hartmut Bögge, and Professor Peter Jutzi as well as to Dr. Hans Pritzkow for performing the X-ray structural analyses of centrohexaindane 1 so far. We thank Dr. Ward T. Robinson for kindly making unpublished results (ref. 24b) available to us, and we also thank Professor Alan P. Marchand for valuable discussions. We also thank Grace AG, Worms, Germany, for a generous gift of chromatographic material. Financial support by the Deutsche Forschungsgemeinschaft (DFG, Ku 663) is gratefully acknowledged.

\section{References}

1 Part 20, D. Kuck, A. Schuster, D. Gestmann and H. Pritzkow, submitted for publication.

2 P. Gund and T. M. Gund, J. Am. Chem. Soc., 1981, 103, 4458.

3 F. Harary, in Chemical Applications of Graph Theory, ed. A. T. Balaban, Academic Press, London, 1976, ch. 2.

4 J. Simon, in Graph Theory and Topology in Chemistry, ed. R. B. King and D. H. Rouvray, Elsevier, Amsterdam, 1987, p. 43.

5 D. M. Walba, Tetrahedron, 1985, 41, 3161 .

6 J.-C. Chambron, C. Dietrich-Buchecker and J.-P. Sauvage, Top Curr. Chem., 1993, 165, 131.

7 H. E. Simmons III and J. E. Maggio, Tetrahedron Lett., 1981, 22, 287

8 H. E. Simmons III, Ph.D. Thesis, Harvard University, 1980.

9 J. E. Maggio, H. E. Simmons III and J. K. Kouba, J. Am. Chem. Soc., 1981, 103, 1579; S. A. Benner, J. E. Maggio and H. E. Simmons III, J. Am. Chem. Soc., 1981, 103, 1581 . 
10 L. A. Paquette and M. Vazeux, Tetrahedron Lett., 1981, 22, 291.

11 D. M. Walba, R. M. Richards and R. C. Haltiwanger, J. Am. Chem. Soc., 1982, 104, 3219.

12 L. A. Paquette, R. V. Williams, M. Vazeux and R. A. Browne, J. Org. Chem., 1984, 49, 2194

13 O. Ermer, Aspekte von Kraftfeldrechnungen, Wolfgang Baur-Verlag, München, 1981, ch. 4.6.3.

14 W. Luef and R. Keese, Helv. Chim. Acta, 1987, 70, 543.

15 D. Kuck, R. A. Krause, D. Gestmann and F. Posteher, manuscript in preparation.

16 D. Kuck, B. Paisdor and D. Gestmann, Angew. Chem., Int. Ed. Engl., $1994,33,1251$.

17 D. Kuck and R. Eckrich, Synlett, 1993, 4, 344; see also: R. Eckrich, Doctoral Thesis, University of Bielefeld, 1993.

18 D. Kuck and A. Schuster, Angew. Chem., Int. Ed. Engl., 1988, 27, 1192.

19 D. Kuck, A. Schuster and R. A. Krause, J. Org. Chem., 1991, 56, 3472.

20 D. Kuck, A. Schuster and D. Gestmann, J. Chem. Soc., Chem. Commun., 1994, 609.

21 L. Pauling and J. Sherman, Proc. Natl. Acad. Sci. USA, 1934, 20, 340.

22 A. Tulinsky and C. R. Worthington, Acta Crystallogr., 1959, 12, 626.

23 A. J. Burn and G. W. Smith, J. Chem. Soc., Chem. Commun., 1965, 394.

24 (a) D. Johnstone, J. E. Fergusson and W. T. Robinson, Bull. Chem. Soc. Jpn., 1972, 45, 3721; (b) N. G. Kinzett, Master's Thesis, University of Canterbury, Christchurch, New Zealand, 1988.

25 C. D. Scattergood, P. G. Bonney, J. M. Slater, C. D. Garner and W. Clegg, J. Chem. Soc., Chem. Commun., 1987, 1749.

26 A. Müller, E. Krickemeyer, A. Hildebrand, H. Bögge, K. Schneider and M. Lemke, J. Chem. Soc., Chem. Commun., 1991, 1685.

27 S. Bernès, F. Sécheresse and Y. Jeannin, Inorg. Chim. Acta, 1992, 191, 11; Y. Jeannin, F. Sécheresse, S. Bernès and F. Robert, Inorg. Chim. Acta, 1992, 198-200, 493.

28 E. H. Braye, L. F. Dahl, W. Hübel and D. L. Wampler, J. Am. Chem. Soc., 1962, 84, 4633.

29 P. Chini, G. Longoni and V. G. Albano, Adv. Organomet. Chem., $1976,14,285$ (see, in particular, pp. 300-306).

30 D. Kuck, in Quasicrystals, Networks and Molecules of Fivefold Symmetry, ed. I. Hargittai, VCH, New York, 1990, ch. 19

31 D. Kuck, R. Eckrich and J. Tellenbröker, J. Org. Chem., 1994, 59, 2511

32 H. W. Thompson, Tetrahedron Lett., 1966, 6489; J. Org. Chem., $1968,33,621$.

33 D. Kuck, Angew. Chem., Int. Ed. Engl., 1984, 23, 508.

34 D. Kuck and H. Bögge, J. Am. Chem. Soc., 1986, 108, 8107.

35 D. Kuck, A. Schuster, B. Ohlhorst, V. Sinnwell and A. de Meijere, Angew. Chem., Int. Ed. Engl., 1989, 28, 595.

36 (a) B. Paisdor and D. Kuck, J. Org. Chem., 1991, 56, 4753; (b) D. Kuck and B. Paisdor, presented in part at the 200th ACS National Meeting of the American Chemical Society, Washington, D.C., 1990, paper ORGN 0316.

37 D. Kuck, T. Lindenthal and A. Schuster, Chem. Ber., 1992, 125, 1449.

38 D. Kuck and M. Seifert, Chem. Ber., 1992, 125, 1461

39 D. Kuck, E. Neumann and A. Schuster, Chem. Ber., 1994, 127, 151.

40 D. Kuck, Chem. Ber., 1994, 127, 409.

41 B. R. Venepalli and W. C. Agosta, Chem. Rev., 1987, 87, 399; W. C. Agosta, in The Chemistry of Alkanes and Cycloalkanes, ed. S. Patai and Z. Rappoport, Wiley, New York, 1992, ch. 20.

42 R. Keese, in Organic Synthesis: Modern Trends, ed. O. Chizhov, Blackwell, Oxford, 1987, p. 43; Nachr. Chem., Tech. Lab., 1982, 30, 844; W. Luef and R. Keese, in Advances in Strain in Organic Chemistry, ed. B. Halton, JAI Press, Greenwich, CT, 1993, vol. 3, p. 229.

43 A. K. Gupta, X. Fu, J. P. Snyder and J. M. Cook, Tetrahedron, 1991. 47, 3665; X. Fu, G. Kubiak, W. Zhang, W. Han, A. K. Gupta and J. M. Cook, Tetrahedron, 1993, 49, 1511 .
44 W. A. Smit, S. M. Buhanjuk, S. O. Simonyan, A. S. Shashkov, Y. T. Struchkov, A. I. Yanovsky, R. Caple, A. S. Gybin, L. G. Anderson and J. A. Whiteford, Tetrahedron Lett., 1991, 32, 2105 .

45 K. Krohn, Nachr. Chem., Tech. Lab., 1987, 35, 264; Organic Synthesis Highlights, ed. J. Mulzer, H.-J. Altenbach, M. Braun, K. Krohn and H.-U. Reissig, VCH, Weinheim, 1991, p. 371.

46 D. Kuck and T. Hackfort, unpublished results.

47 D. Gestmann, Doctorial Thesis, University of Bielefeld, 1994.

48 I. Ya. Shternberga and Ya. F. Freimanis, J. Org. Chem. USSR (Engl. Transl.), 1968, 4, 1044; Latv. PSR Zinat. Akad. Vestis, Kim. Ser., 1972, 207 (Chem. Abstr., 1972, 77, 101036m); Yu. Yu. Popelis, V. A. Pestunovich, I. Ya. Shternberga and Ya. F. Freimanis, J. Org. Chem. USSR (Engl. Transl.), 1972, 8, 1907.

49 W. Ten Hoeve and H. Wynberg, J. Org. Chem., 1979, 44, 1508.

50 (a) A. Schuster and D. Kuck, Angew. Chem., Int. Ed. Engl., 1991, 30, 1699; (b) A. Schuster, Doctoral Thesis, University of Bielefeld, 1991.

51 D. Kuck, A. Schuster, C. Fusco, M. Fiorentino and R. Curci, J. Am. Chem. Soc., 1994, 116, 2375.

52 D. Kuck, A. Schuster, W. Saak and S. Pohl, manuscript in preparation.

53 R. Hoffmann, R. Alder and C. F. Wilcox, J. Am. Chem. Soc., 1970,92, 4992; R. Hoffmann, Pure Appl. Chem., 1971, 28, 181.

54 J. Chadrasekhar, E.-U. Würthwein and P. v. R. Schleyer, Tetrahedron, 1981, 37, 921; E.-U. Würthwein, J. Chadrasekhar, E. D. Jemmis and P. v. R. Schleyer, Tetrahedron Lett., 1981, 22, 843.

55 M. C. Böhm, R. Gleiter and P. Schang, Tetrahedron Lett., 1979, 2575.

56 M. P. McGrath and L. Radom, J. Am. Chem. Soc., 1993, 115, 3320; J. E. Lyons, D. R. Rasmussen, M. P. McGrath, R. H. Nobes and L. Radom, Angew. Chem., 1994, 106, 1722.

57 G. Erker, R. Zwettler, C. Krüger, R. Noe and S. Werner, J. Am. Chem. Soc., 1990, 112, 9620; M. Albrecht, G. Erker and C. Krüger, Synlett, 1993, 441

58 H. Hart, Th. Sulzberg and R. R. Rafos, J. Am. Chem. Soc., 1963, 85, 1800 .

59 T.-L. Ho, Tandem Organic Reactions, Wiley, New York, 1992.

60 R. A. Krause, Doctoral Thesis, University of Bielefeld, 1992; D. Kuck and R. A. Krause, manuscript in preparation.

61 T. Prange, J. Drouin, F. Leyendecker and J.-M. Conia, J. Chem. Soc., Chem. Commun., 1977, 430.

62 A. Schönberg and M. Mamluk, Chem. Ber., 1973, 106, 849

63 D. Kuck, K. Schmitz and R. Wolf, unpublished results.

64 A. Schönberg and M. M. Sidky, Chem. Ber., 1974, 107, 2341.

65 H. Butenschön and A. de Meijere, Chem. Ber., 1985, 118, 2757.

66 L. A. Paquette, Y. Miyahara and C. W. Doecke, J. Am. Chem. Soc., 1986, 108, 1716; L. A. Paquette and Y. Miyahara, J. Org. Chem., $1987,52,1265$.

67 R. Köster and A.-A. Pourzal, Ger. Offen., 2417 357, 1975 (Chem. Abstr., 1976, 84, 16961j).

68 G. Wittig and M. Leo, Ber. Dtsch. Chem. Ges., 1931, 64, 2395; G. Pifferi, A. Vigevani and P. Consonni, Ann. Chim. (Rome), 1968, 58, 1294.

69 R. Zagats and G. Vanags, Latv. PSR Zinat. Akad. Vestis, Khim. Ser., 1963, 725 (Chem. Abstr., 1964, 61, 3034g).

70 American Petroleum Institute (API), Research Project 44/II 1950, $400 ; 1951,414$.

71 H. Müller-Bötticher, W.-D. Fessner, J.-P. Melder, H. Prinzbach, S. Gries and H. Irngartinger, Chem. Ber., 1993, 126, 2275.

72 B. Paisdor, H.-F. Grützmacher and D. Kuck, Chem. Ber., 1988, 121, 1307.

Paper 4/05308G

Received 31 st August 1994 Accepted 12th October 1994 